\title{
Implementation of a Novel MPPT Tactic for PV System Applications on MATLAB/Simulink and Proteus-Based Arduino Board Environments
}

\author{
Abdelkhalek Chellakhi $\mathbb{D}^{1},{ }^{1}$ Said El Beid $\mathbb{D},{ }^{2}$ and Younes Abouelmahjoub $\mathbb{D}^{1}$ \\ ${ }^{1}$ National School of Applied Sciences, LabSIPE, Chouaib Doukkali University, El Jadida 24000, Morocco \\ ${ }^{2}$ CISIEV Team, Cadi Ayyad University, Marrakech 40160, Morocco \\ Correspondence should be addressed to Abdelkhalek Chellakhi; chellakhi.a@ucd.ac.ma
}

Received 7 December 2020; Accepted 9 February 2021; Published 10 March 2021

Academic Editor: Huiqing Wen

Copyright ( 2021 Abdelkhalek Chellakhi et al. This is an open access article distributed under the Creative Commons Attribution License, which permits unrestricted use, distribution, and reproduction in any medium, provided the original work is properly cited.

\begin{abstract}
This paper is aimed at harvesting the photovoltaic systems extracting power under difficult irradiance and load conditions, by proposing a novel maximum power point tracking (MPPT). This proposed MPPT tactic has been examined under various climatic and load conditions using two powerful and accurate simulation environments for PV systems, MATLAB/Simulink and Proteus. The first implementation using the MATLAB/Simulink software was carried out to examine the performance of the novel MPPT tactic under sudden insolation and load change, where the second implementation using the Proteus software was carried out in order to prove that the novel MPPT tactic can be easily implemented using low-cost components, Arduino board, and LCD display. The simulation results prove that the novel MPPT tactic has a high convergence speed to locate the MPP, especially at fast solar irradiation and load variation with zero oscillation under steady-state operation, which takes less than 9.6 milliseconds (ms) under the MATLAB/Simulink software and 0.24 microseconds ( $\mu$ s) under Proteus environment. That means it is about six times faster than P\&O and five times faster than INC MPPT methods, and its tracking efficiency is between 99.40\% and 99.86\%. Furthermore, the novel MPPT tactic shows the best tracking accuracy and better ability to mitigate power losses under overall simulation scenarios compared with other traditional MPPT methods.
\end{abstract}

\section{Introduction}

Without a doubt, renewable energy sources will be the world's key source of power within two decades, and their establishments in the global energy system will be faster than at any time. Photovoltaic or solar energy is one of several free, sustainable, and abundant renewable energies (wind, hydropower, tide, biomass, geothermal, and so on), which can be harvested from natural renewable resources. Thanks to its abundance and cleanness, photovoltaic energy, pollute less, and its conversion technology in the last decades getting improved.

Photovoltaic (PV) generators can be used for various aspects, like grid-connected, stand-alone battery charging, building-integrated domestic electric supply, and pumping systems. On the other hand, PV generator is affected by variable weather conditions such as solar irradiation and ambient temperature, which cause a change current, voltage, and maximum power point of PV panels. In addition, it suffers from low conversion efficiency, which lies in the range of $15-20 \%$. In order to enhance the PV system's efficiency and decrease its power losses, it is necessary to operate the PV panel at its maximum power point (MMP). This MPP can be extracted by a specific mechanism called maximum power point tracking (MPPT) [1].

MPPT is aimed at extracting the available maximum power generated by the PV panel under different climatic conditions (temperature and solar irradiation). MPPT control aging on DC-DC converter, which is located between the PV generator and the load, in order to adapt and control 
the power delivered by the PV generator and that, requires the load. Thus, the MPP is reached by adjusting the duty cycle of the DC-DC converter by the MPPT algorithm.

Maximum power point tracking has been employed in different PV system configurations, stand-alone, and gridconnected PV systems. For the stand-alone PV systems, many MPPT algorithms have been proposed recently in the scientific literature [1-5]. Nevertheless, it remains the most used from the existing MPPT algorithms in the literature for the stand-alone PV systems: perturb and observe (P\&O) $[2,6]$, increment of conductance (INC) $[7,8]$, hill climbing (HC) $[9,10]$, and fuzzy logic (FLC) [11-13] MPPT methods, according to their simplicity and ease of implementation. These methods differ in many terms, such as time convergence speed, cost, performance, sensors used, and implementation. Nevertheless, they suffer from several shortcomings, such as slow tracking speed at sudden environment condition variation and PV output power's steady-state error around the MPP, which consequently leads to greater power losses from the PV array [1].

Recently, numerous MPPT methods have been proposed to deal with these aforementioned drawbacks $[1,3,5]$. In [1], a novel MPPT tactic is proposed to surmount famous shortcomings of the existing MPPTs in the literature (P\&O, INC, $\mathrm{HC}$, etc.), such as slow converging speed under fast solar irradiation variation and the oscillation around the MPP at steady-state operation. Furthermore, the proposed MPPT tactic has a good performance to track MPP with high convergence speed and zero oscillation; in addition, this technique is expected to reduce the power loss and improve the response speed of tracking [1].

This paper is an extension of work originally presented in the 2020 5th International Conference on Renewable Energies for Developing Countries (REDEC) [1]. In this work, the novel MPPT tactic is implemented under two celebrate simulation environments, MATLAB/Simulink and Proteus, in order to examine its efficiency and performance to track the MPP under different simulation scenarios of solar irradiation and load variation.

Simulation results are proven the effectiveness and robustness of the proposed MPPT tactic compared to other MPPT algorithms such as P\&O, INC, and FLC to track the real MPP of the PV generator under various solar irradiation and load levels.

The remaining of this work is chained as follows: Section 2 explains the basic model and characteristic analysis of the PV module. Section 3 presents and explains the principle of the proposed MPPT tactic. Next, the simulation results obtained by using MATLAB/Simulink and Proteus software are described in Section 4. Finally, the conclusion of this paper is reported in Section 5.

\section{Basic Model and Characteristic Analysis of PV Module}

This section is divided into two subsections. Subsection one will present the basic equivalent circuit and characteristics of a PV module. Moreover, subsection two will study the DC-DC boost converter.

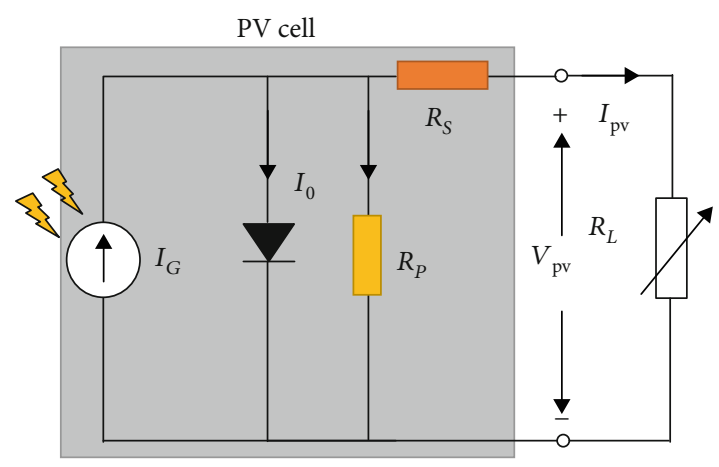

FIGURE 1: Equivalent circuit of solar cell.

2.1. Basic Photovoltaic Model. PV cell also known as a solar power cell is the basic model unit of the PV module. Many PV cells are connected in series or/and parallel to produce the appropriate current and voltage.

The PV cell equivalent circuit model is shown in Figure 1, which consists of two resistances and a diode. The losses which small leakage current flows through the parallel path are represented with a parallel $R_{P}$ resistance, the losses which are loss of metal grid contacts and current collecting bus are represented by a series $R_{S}$ resistance, and the cross current which associated with $p-n$ junctions in semiconductor devices is represented with a diode $[14,15]$.

The PV panel output current $I_{\mathrm{pv}}$ expression according to the equivalent circuit shown in Figure 1 can be expressed as follows:

$$
\begin{aligned}
I_{\mathrm{pv}}= & n_{P} \underset{I_{G}}{\times}-n_{P} \times I_{o}\left(\exp \left(\frac{q \times\left(V_{\text {out }}+I_{\text {out }} \times R_{S}\right)}{A \times K \times T \times n_{S}}\right)-1\right)-n_{P} \\
& \times \frac{\left(V_{\text {out }}+I_{\text {out }} \times R_{S}\right)}{n_{S} \times R_{P}}
\end{aligned}
$$

where $I_{\mathrm{pv}}$ and $V_{\mathrm{pv}}$ are the current and voltage at the terminals of the PV cell, $I_{G}$ is the light current of the PV cell, $I_{0}$ characterizes the reverse diode saturation current, $n_{P}$ and $n_{S}$ are the numbers of solar cells in parallel and series, respectively. The electronic charge value $q$ is $\left(1.6 \times 10^{-19} \mathrm{C}\right), A$ is the ideality factor, $K$ is the Boltzmann's constant $\left(8.65 \times 10^{-5} \mathrm{eV} / \mathrm{K}\right)$, and $T$ is the $\mathrm{p}-\mathrm{n}$ junction temperature $(\mathrm{K})[11]$.

The PV cell output current shows a nonlinear characteristic as reported in equation (1), and it can be greatly influenced by insolation and ambient temperature.

The dependence of the PV cell light current $I_{G}$ with temperature and solar irradiation is given as follows:

$$
I_{G}=\left[I_{s} \times k_{i}\left(T+T_{r}\right)\right] \frac{G}{100},
$$

where $k_{i}$ is the temperature coefficient, $T_{r}$ is the reference temperature of the $\mathrm{PV}$ cell $\left({ }^{\circ} \mathrm{C}\right), G$ is solar irradiation 


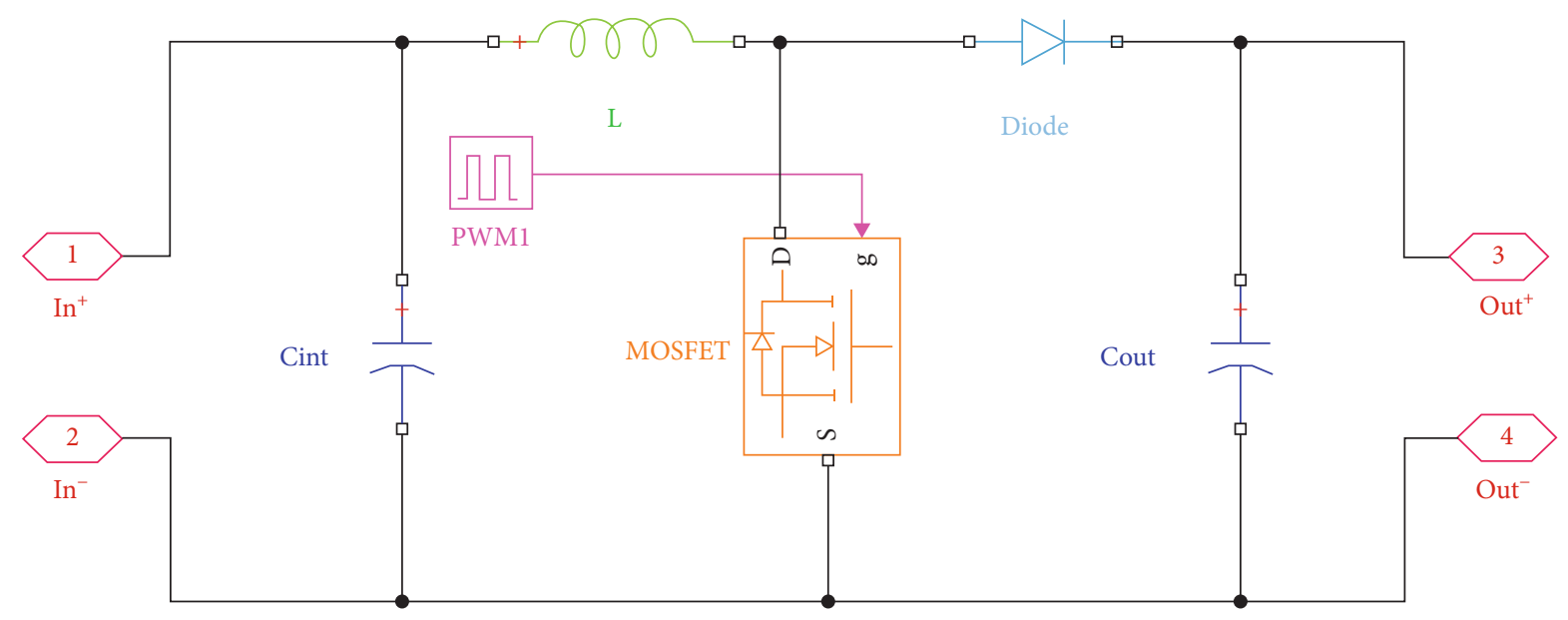

FIGURE 2: DC-DC boost converter circuit.

$\left(\mathrm{W} / \mathrm{m}^{2}\right)$, and $I_{s}$ is the saturation current which can be written as follows:

$$
I_{s}=I_{\text {os }} \times\left(\frac{T}{T_{r}}\right)^{3} \times \exp \left(\left(-\frac{q \times E_{g}}{A \times K}\right) \times\left(\frac{1}{T_{r}}+\frac{1}{T}\right)\right],
$$

where $I_{\mathrm{os}}$ is the reverse saturation current at $T_{r}$ and $E_{g}$ is the bandgap energy of the semiconductor of the PV cell.

2.2. DC-DC Boost Converter. The most frequently used from DC-DC converters in photovoltaic power conversion is the DC-DC boost converter shown in Figure 2 which is the most popular one, which ensures a better maximum power transfer between PV panel and load, with fewer losses of energy $[14,16]$.

The duty ratio of the DC-DC converter is regulated using the maximum power point tracking (MPPT) algorithm in order to match the source and load operating point at the maximum power point. To reach a higher conversion efficiency with electrical circuit simplicity, a DC-DC boost converter is chosen to be used in this study, contrary to other complex configurations [9].

To reduce the power losses at high frequencies, the MOSFET is used as the switching device, which can be controlled by a PWM signal.

The relationships of input and output side of the boost converter in case of the voltage and current are obtained as follows:

$$
\begin{gathered}
V_{\text {out }}=V_{\mathrm{pv}} \frac{1}{1-d}, \\
I_{\text {out }}=I_{\mathrm{pv}}(1-d) .
\end{gathered}
$$

Derivation of (3) by (5) provides the following:

$$
R_{\text {out }}=\frac{V_{\text {out }}}{I_{\text {out }}}=\frac{1}{(1-d)^{2}} \times \frac{V_{\mathrm{pv}}}{I_{\mathrm{pv}}}=\frac{1}{(1-d)^{2}} \times R_{\mathrm{in}}
$$

where $R_{\text {in }}$ and $R_{\text {out }}$ present the input and output resistance side of the boost converter, respectively.
The equation (6) can be expressed in a PV system as follows:

$$
R_{\mathrm{load}}=\frac{R_{\mathrm{pv}}}{(1-d)^{2}}
$$

where $R_{\text {load }}$ presents the load resistance and $R_{\mathrm{pv}}$ presents the resistance seen by the PV string.

From (7), the boost converter's duty ratio can be expressed as follows:

$$
d=1-\sqrt{\frac{R_{\mathrm{pv}}}{R_{\mathrm{load}}}} .
$$

\section{The Principle of the Proposed MPPT Tactic}

In order to surmount the weaknesses of several MPPT methods, this new MPPT method is proposed. Furthermore, the principle of this method is based on the maximum power point's area shown in Figure 3, where you can obviously see that the maximum power point's zone is located in a very narrow region of the maximum power point voltages $V$ mpps and it is limited by $V_{\operatorname{mppmin}}$ et $V_{\operatorname{mppmax}}$ [1].

Firstly and according to the PV array current and voltage measurement, the actual voltage $V(k)$ is compared with $V_{\text {mppmin }}$ and $V_{\text {mppmax }}$ voltages. If the actual voltage $V(k)$ is greater than $V_{\text {mppmax }}$, it receives the value of $V_{\operatorname{mppmax}}$, and if the $V(k)$ is less than $V_{\text {mppmin }}$, it receives the value of $V_{\text {mppmin }}$. Secondly, when the regulation of the PV panel voltage is made, the below equation (9) is used for calculating the new duty ratio of the boost converter [1]:

$$
d(k+1)=1-\sqrt{\frac{V(k) / I(k)}{R_{\text {load }}}} .
$$

Finally, the new duty ratio $d(k+1)$ receives the last duty ratio $d(k)$ value, if $V(k)$ is within the range ( $V_{\text {mppmin }}$ to $\left.V_{\text {mppmax }}\right)$. Thus, these operations allow the novel MPPT 


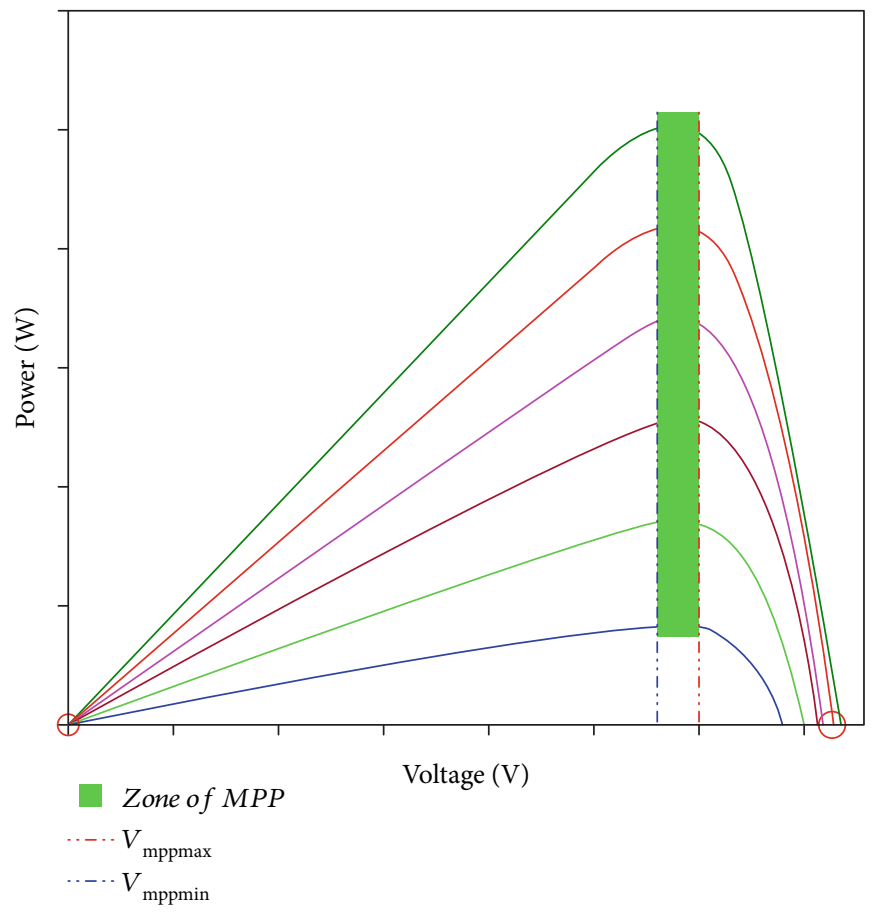

FIgURE 3: Zone of MPP illustration of the proposed MPPT tactic in the PV characteristic of the PV panel.

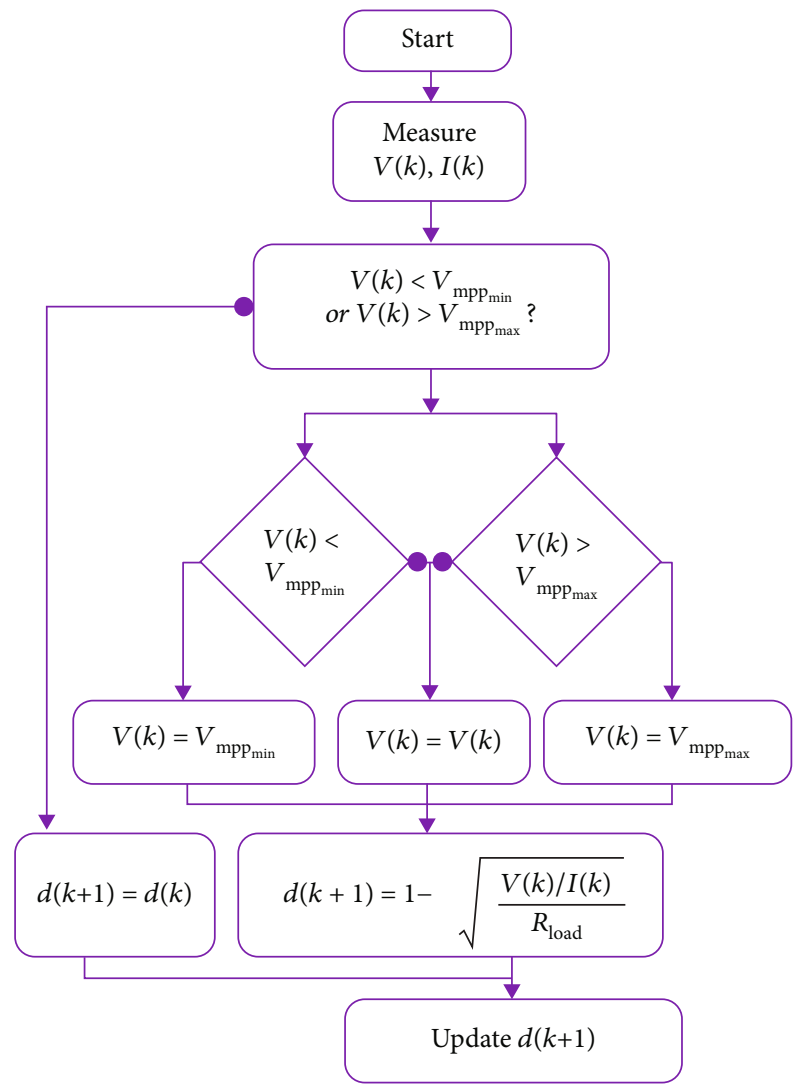

FIgURE 4: The novel MPPT tactic flowchart.

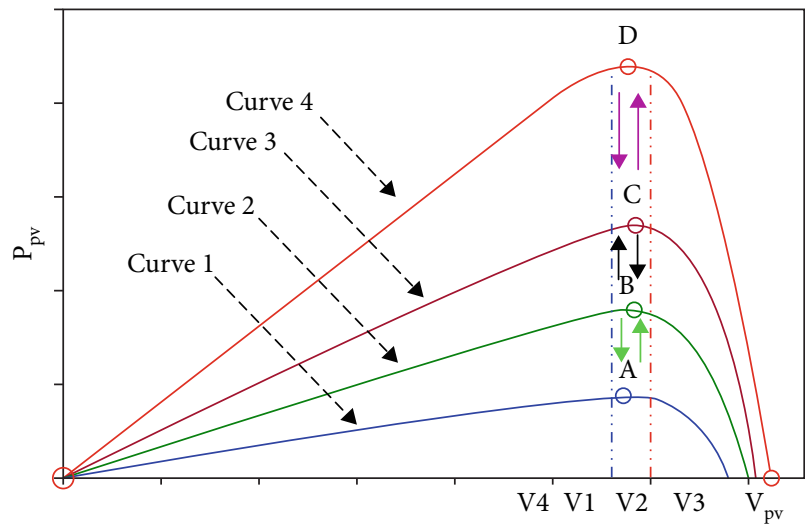

FIGURE 5: PV panel's $P_{\mathrm{pv}}-V_{\mathrm{pv}}$ curves under fast changing of solar irradiation.

control to focus the MPP area with a high precision and convergence speed [1].

As a conclusion, from the novel MPPT's flowchart shown in Figure 4, a direct control strategy can be achieved to track the real MPP by the PV voltage regulation.

The solar irradiation level suddenly increases or decreases as shown in Figure 5, which illustrates the PV module's $P_{\mathrm{pv}}-V_{\mathrm{pv}}$ characteristics under four levels of insolation, with corresponding MPPs at points $\mathrm{A}, \mathrm{B}, \mathrm{C}$, and D. The proposed MPPT method operates consistently at the MPP, during this process. Therefore, the actuating points' curve 1 , curve 2, curve 3 , and curve 4 are located at points A, B, $\mathrm{C}$, and D, respectively. As a result, the proposed MPPT algorithm has good reliability, and it is appropriate for 


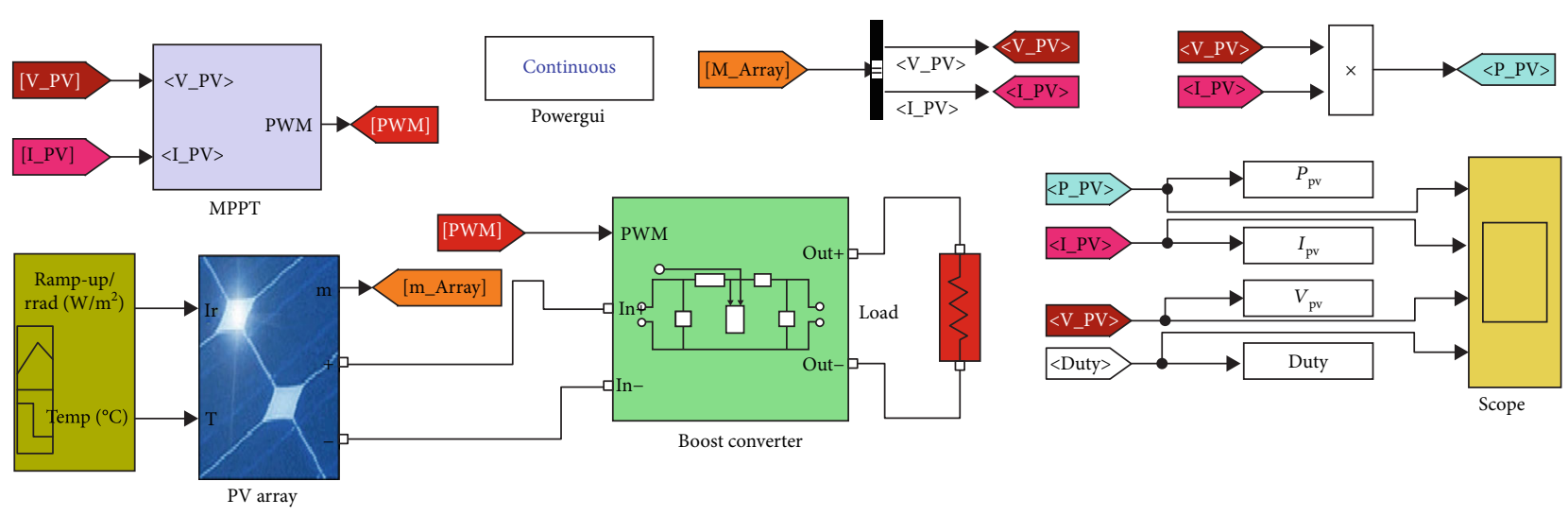

Figure 6: Simulink implementation of the novel MPPT with the overall PV system.

implementation under several insolation conditions, especially under the fast change of the insolation [1].

\section{Simulation Results}

To show the validity and performance of the proposed MPPT technique, numerous simulation scenarios under several environmental conditions are carried out. The simulation implementation is developed numerically using two well-known environments, MATLAB/Simulink and Proteus software

4.1. MATLAB/Simulink Environment Implementation. The overall MATLAB/Simulink implementation is shown in Figure 6, which includes a PV generator, DC-DC boost converter, maximum power point tracking (MPPT) algorithm, and a resistive load. The used PV panel and boost converter specifications are listed in Table 1.

In this part of the simulation, as shown in Figures 7-9, three scenarios of solar irradiation variation are carried out in order to investigate the performance and accuracy of the proposed MPPT tactic to track the available power under different insolation conditions and transition levels, where the proposed MPPT tactic is compared with other famous MPPT algorithms such as P\&O, INC, and the fuzzy logic in [14]. Furthermore, the simulation results with these three different scenarios are shown in Figures 10-15.

In the scenario I, the solar irradiation is set at $800 \mathrm{~W} / \mathrm{m}^{2}$, and then, it varies suddenly between three levels $1200 \mathrm{~W} / \mathrm{m}^{2}$, $400 \mathrm{~W} / \mathrm{m}^{2}$, and $900 \mathrm{~W} / \mathrm{m}^{2}$, as shown in Figure 7. For scenario II, the solar irradiance is increased continuously from $400 \mathrm{~W} / \mathrm{m}^{2}$ to $1200 \mathrm{~W} / \mathrm{m}^{2}$, and then, it decreased continuously from $1200 \mathrm{~W} / \mathrm{m}^{2}$ to $400 \mathrm{~W} / \mathrm{m}^{2}$, as presented in Figure 8. In addition, Figure 9 shows the scenario III of the solar irradiation, where a slow variation of the insolation (Sin form) is presented.

4.2. Fast Solar Irradiation Variation. The first scenario I's simulation results of the proposed MPPT technique compared with the P\&O, INC, and FLC MPPT techniques are shown in Figures 9 and 10. In this scenario, the temperature was kept constant at $25^{\circ} \mathrm{C}$, and the insolation levels are shown in Figure 7.
TABLE 1: PV system parameters (1Soltech 1STH-215-P PV module at STC: temperature $=25^{\circ} \mathrm{C}$, insolation $=1000 \mathrm{~W} / \mathrm{m}^{2}$, and boost converter circuit).

\begin{tabular}{lc}
\hline Parameters & Value \\
\hline Maximum power $\left(P_{\text {mpp }}\right)$ & $212.93 \mathrm{~W}$ \\
Voltage at MPP $\left(V_{\text {mpp }}\right)$ & $29 \mathrm{~V}$ \\
Current at MPP $\left(I_{\text {mpp }}\right)$ & $7.35 \mathrm{~A}$ \\
Open circuit voltage $\left(V_{\text {OC }}\right)$ & $36.3 \mathrm{~V}$ \\
Short circuit current $\left(I_{\text {sc }}\right)$ & $7.84 \mathrm{~A}$ \\
Temperature coefficient of $\left(V_{\text {oC }}\right)$ & $-0.36099 \% /{ }^{\circ} \mathrm{C}$ \\
Temperature coefficient of $\left(I_{\mathrm{sc}}\right)$ & $0.102 \% /{ }^{\circ} \mathrm{C}$ \\
Input capacitor & $47 \mu \mathrm{F}$ \\
Output capacitor & $470 \mu \mathrm{F}$ \\
Inductance & $1 \mathrm{mH}$ \\
Switching frequency & $10 \mathrm{kHz}$ \\
Load resistance & $30 \Omega$ \\
\hline
\end{tabular}

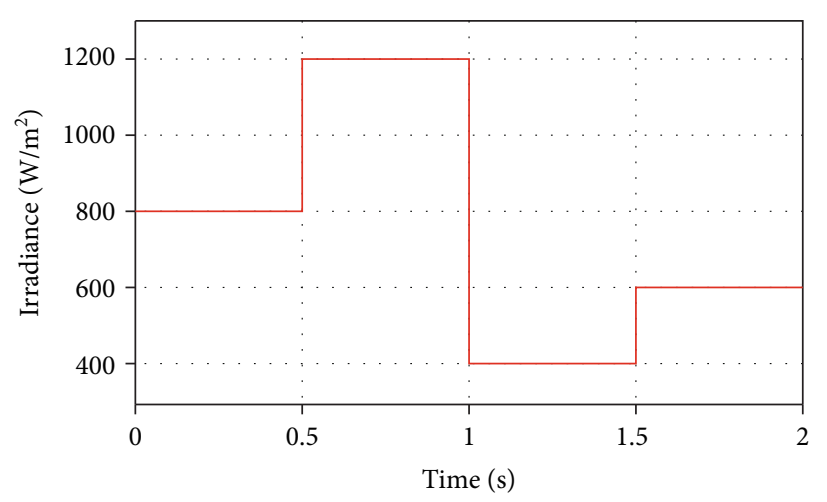

Figure 7: Scenario I insolation levels.

Figure 10 presents the PV panel's output power simulation results of the novel MPPT technique, compared with the aforementioned MPPT techniques under the scenario I of insolation. Based on this Figure 10, the P\&O and INC methods are unable to track the real MPP under the scenario I and have a large steady-state ripple, especially at a high level of solar irradiation. On the other hand, the available maximum power is tracked perfectly with high-speed convergence 


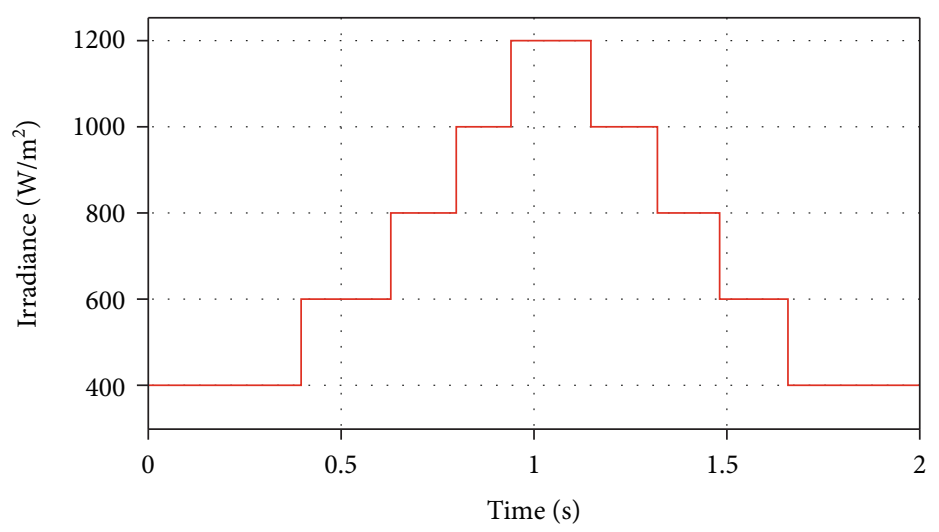

Figure 8: Scenario II insolation levels.

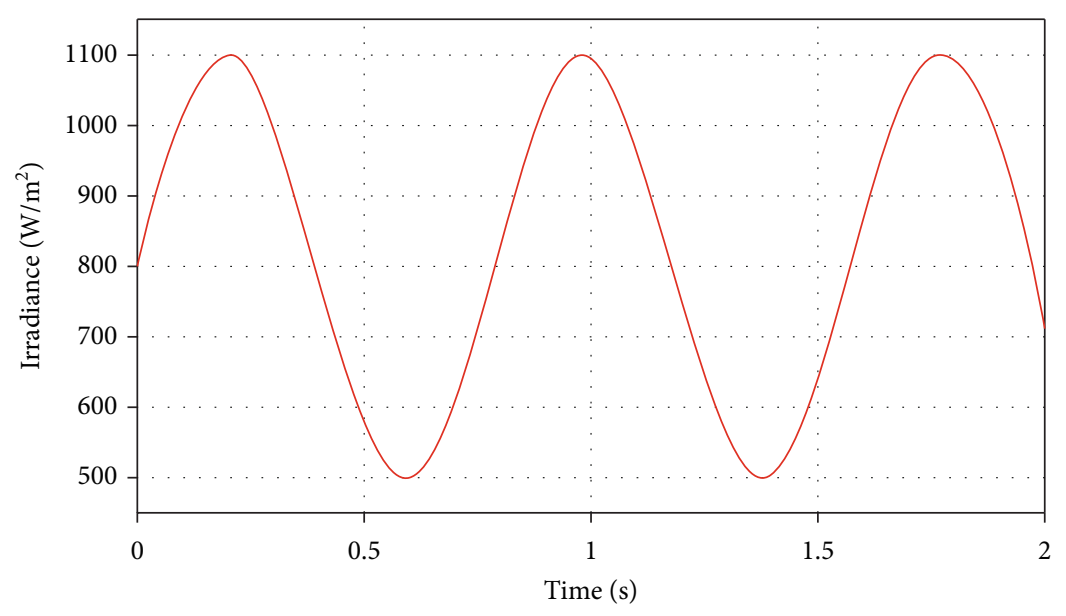

FIgURE 9: Scenario III insolation levels.

and zero oscillation using the novel MPPT algorithm as can be seen in the zoomed portions. In addition, the FLC method is not able to follow the MPP under fast insolation variation and loses its tracking during the whole test time.

Furthermore, the novel MPPT technique has a good performance to stabilize the output power, current, and voltage of the PV generator with neglected steady-state error. This stability can be a result of the generated duty ratio of the boost converter, which varies perfectly as soon as the solar irradiation varies, and kept stable at steady-state operation as shown in Figure 10, whereas the $\mathrm{P} \& \mathrm{O}$ and INC methods present bad performance of stability in the PV generator output power, current, and voltage at steady-state operation. This instability is a result of the three-level oscillations in the duty ratio of the boost converter as can be observed in the zoomed portions of Figure 11, which conducted to an extra loss of energy power.

Figures 12 and 13 present the scenario II simulation results. This scenario II is proposed in order to examine the performance of the novel MPPT tactic to track the MPP under the continual sudden increase and decrease of the solar irradiation levels.

Figure 12 shows the PV panel output power simulation results of the comparison of the novel MPPT technique with the P\&O, INC, and FLC methods. Based on this Figure, all MPPT techniques can follow the MPP except the FLC MPPT, which cannot reach the MPP, especially under low solar irradiation. The P\&O and INC MPPT methods can follow the MPP but their tracking speed is slow to reach the MPP at sudden insolation variation, which results in an extra power loss. In addition, a huge oscillation around the MPP at steady-state operation is obtained, especially at high solar irradiation levels. On the opposition side, the proposed MPPT tactic tracks perfectly the real maximum power during the whole test time and has a high accuracy to fetch the MPP with less time convergence at sudden insolation variation. On top of that, it can track the available power with zero ripples around the MPP.

The PV panel output current and voltage with the duty cycle of the boost converter under the second scenario of solar irradiation variation are shown in Figure 13, where the novel MPPT tactic presents better stability in the output current and voltage, compared to the P\&O, INC, and FLC MPPT techniques.

4.3. Slow Solar Irradiation Variation. Scenario III is proposed in order to show the dynamic behavior of the proposed MPPT method under this kind of solar irradiation variation 


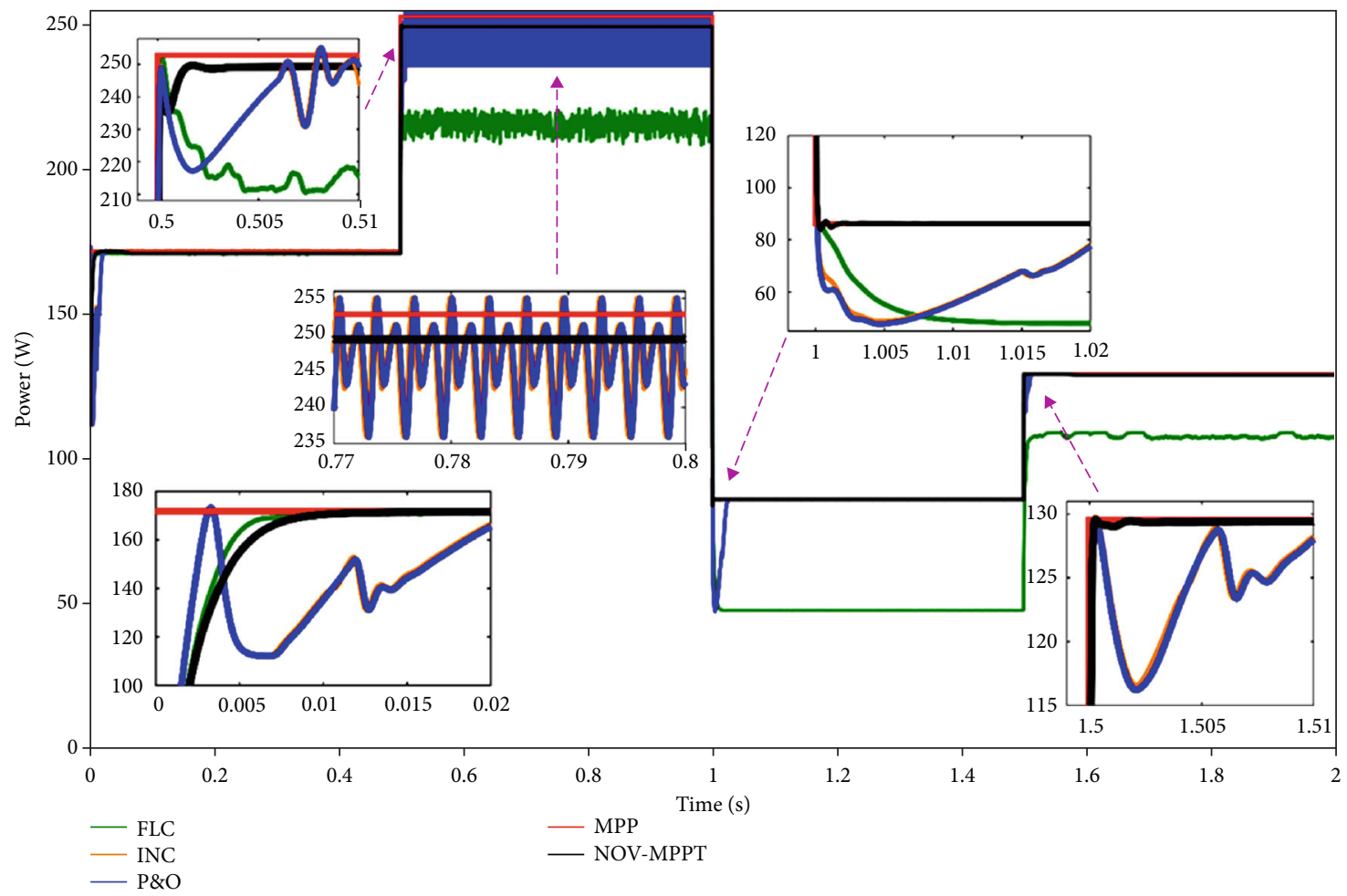

FIGURE 10: The proposed MPPT PV output power's simulation result compared to the P\&O, INC, and FLC MPPT methods under scenario I of insolation variation.
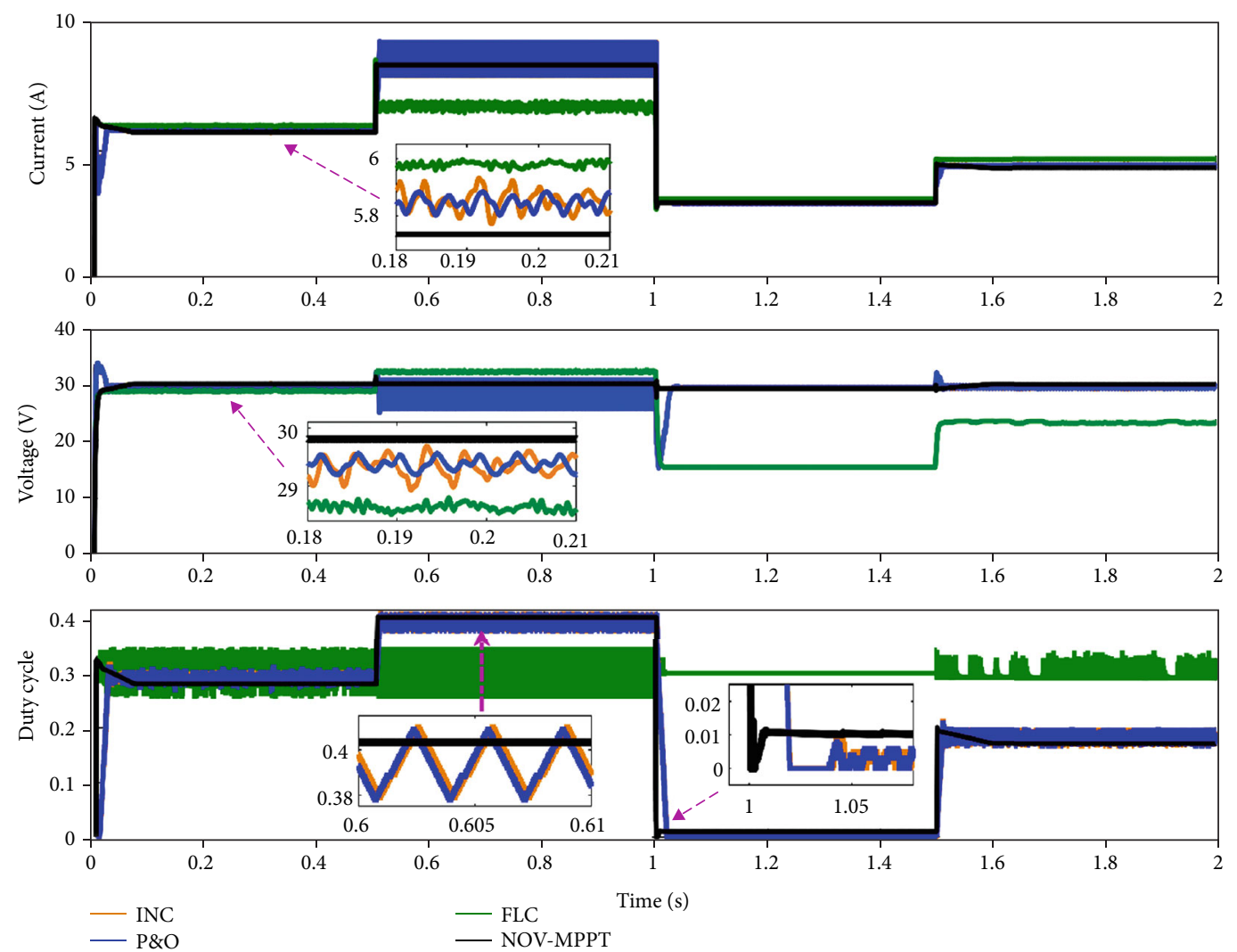

FIGURE 11: PV output current and voltage with duty cycle simulation results of the proposed MPPT compared to the P\&O, INC, and FLC MPPT methods under scenario I of insolation variation. 


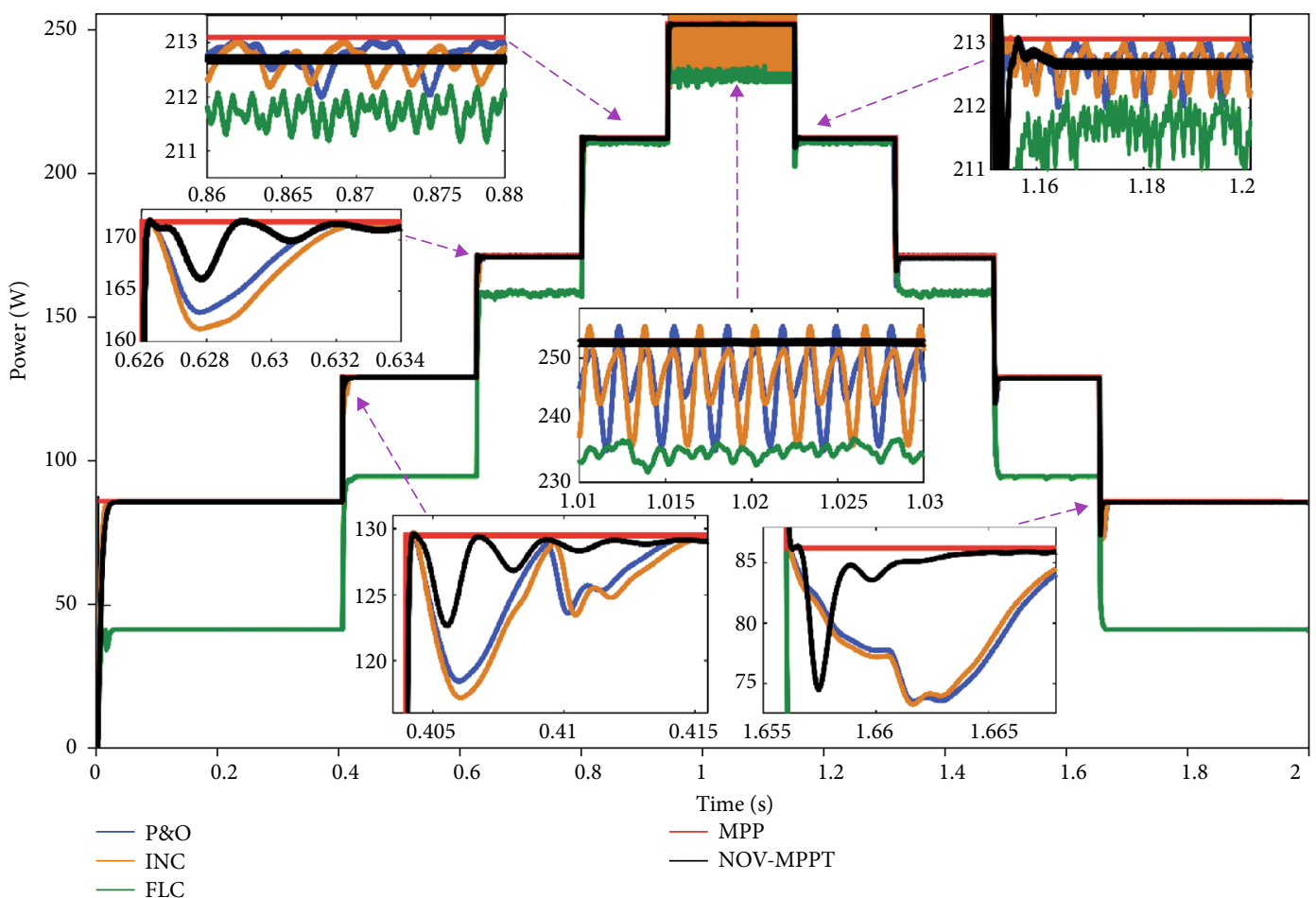

FIGURE 12: The proposed MPPT PV output power's simulation results compared to the P\&O, INC, and FLC MPPT methods under the solar irradiation variation scenario II.
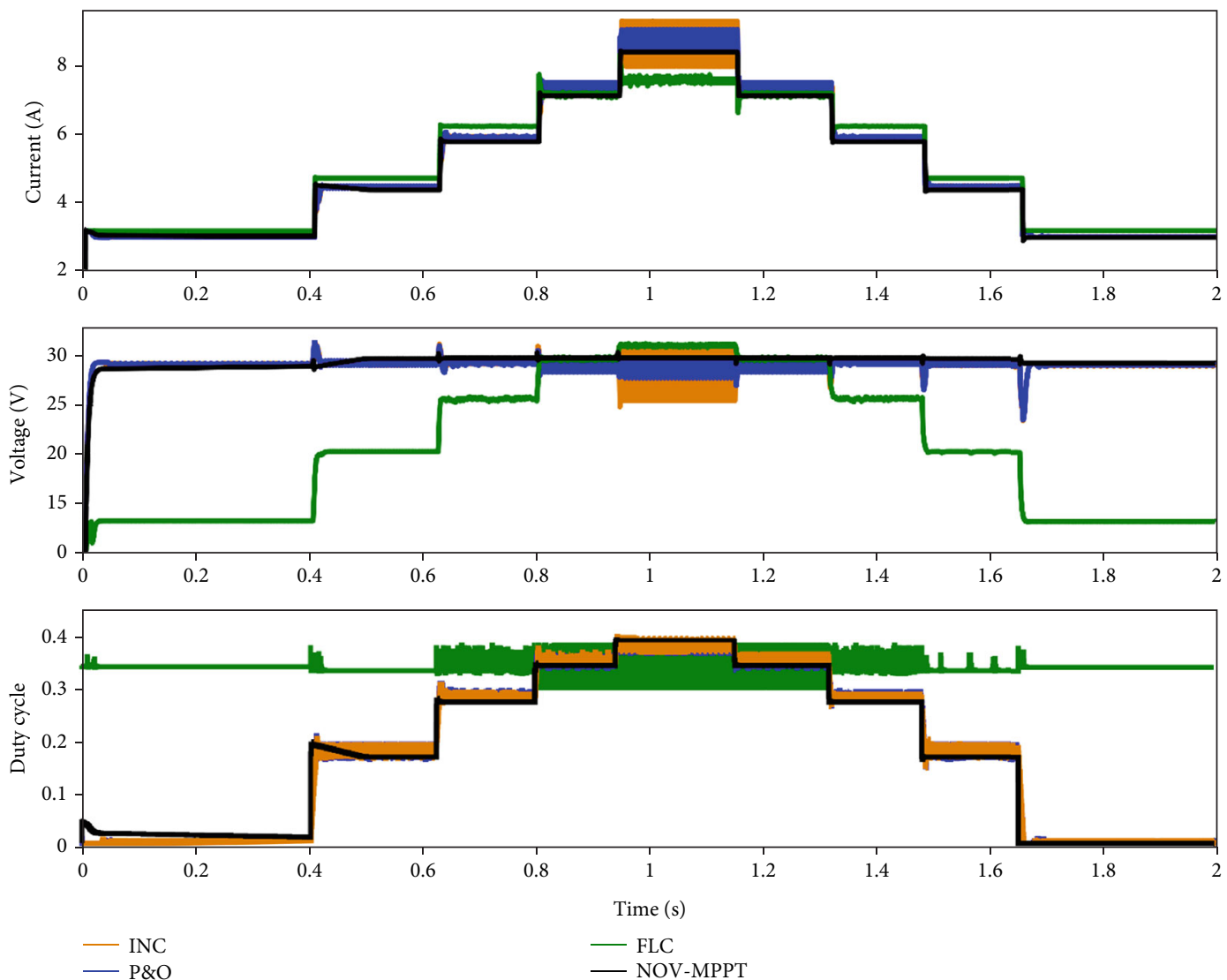

FIGURE 13: PV output current and voltage with duty cycle simulation results of the proposed MPPT compared to the P\&O, INC, and FLC MPPT methods under the solar irradiation variation scenario II. 


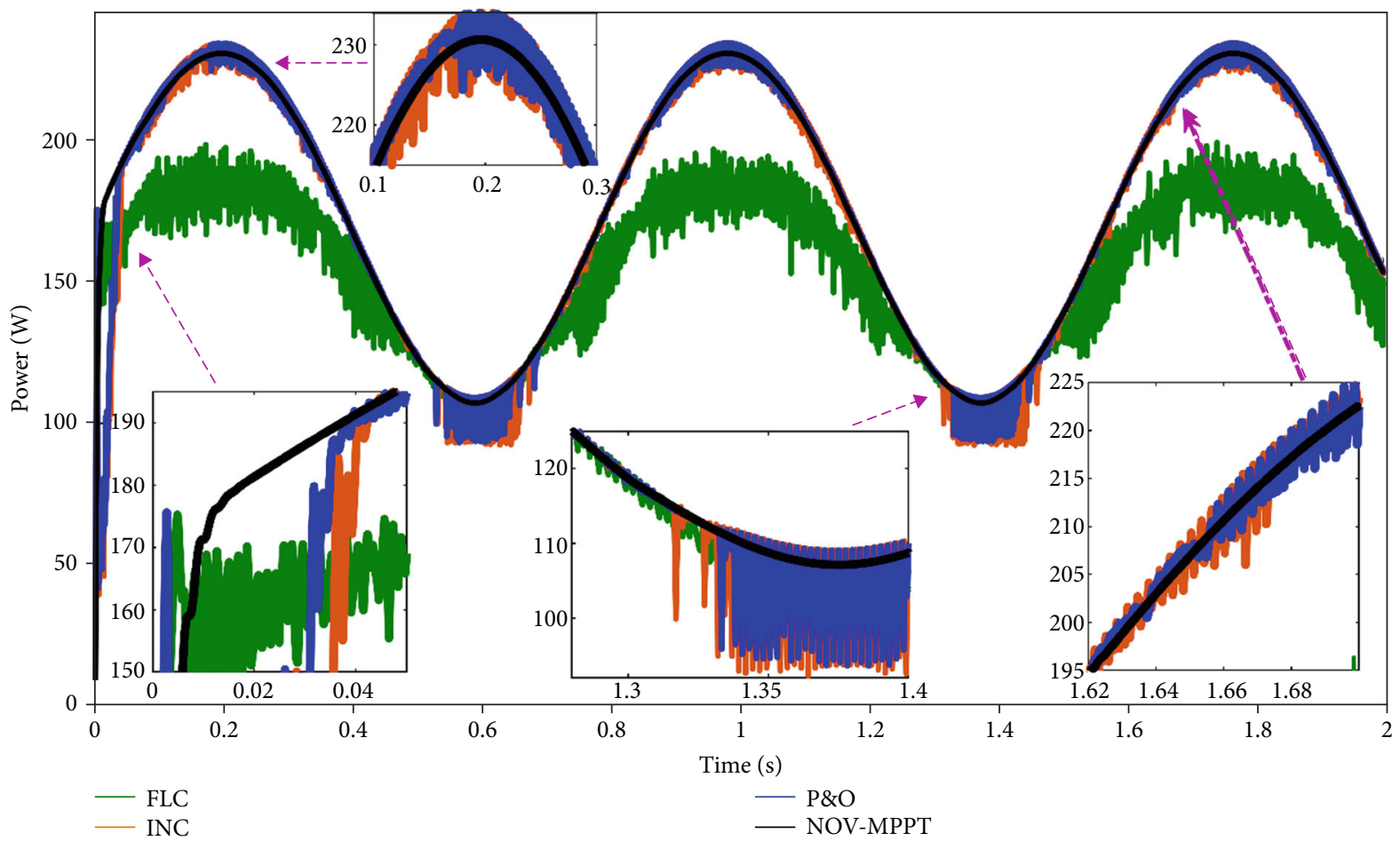

FIGURE 14: PV output power simulation result comparison of the proposed MPPT with the P\&O, INC, and FLC MPPT methods under the solar irradiation variation scenario III.
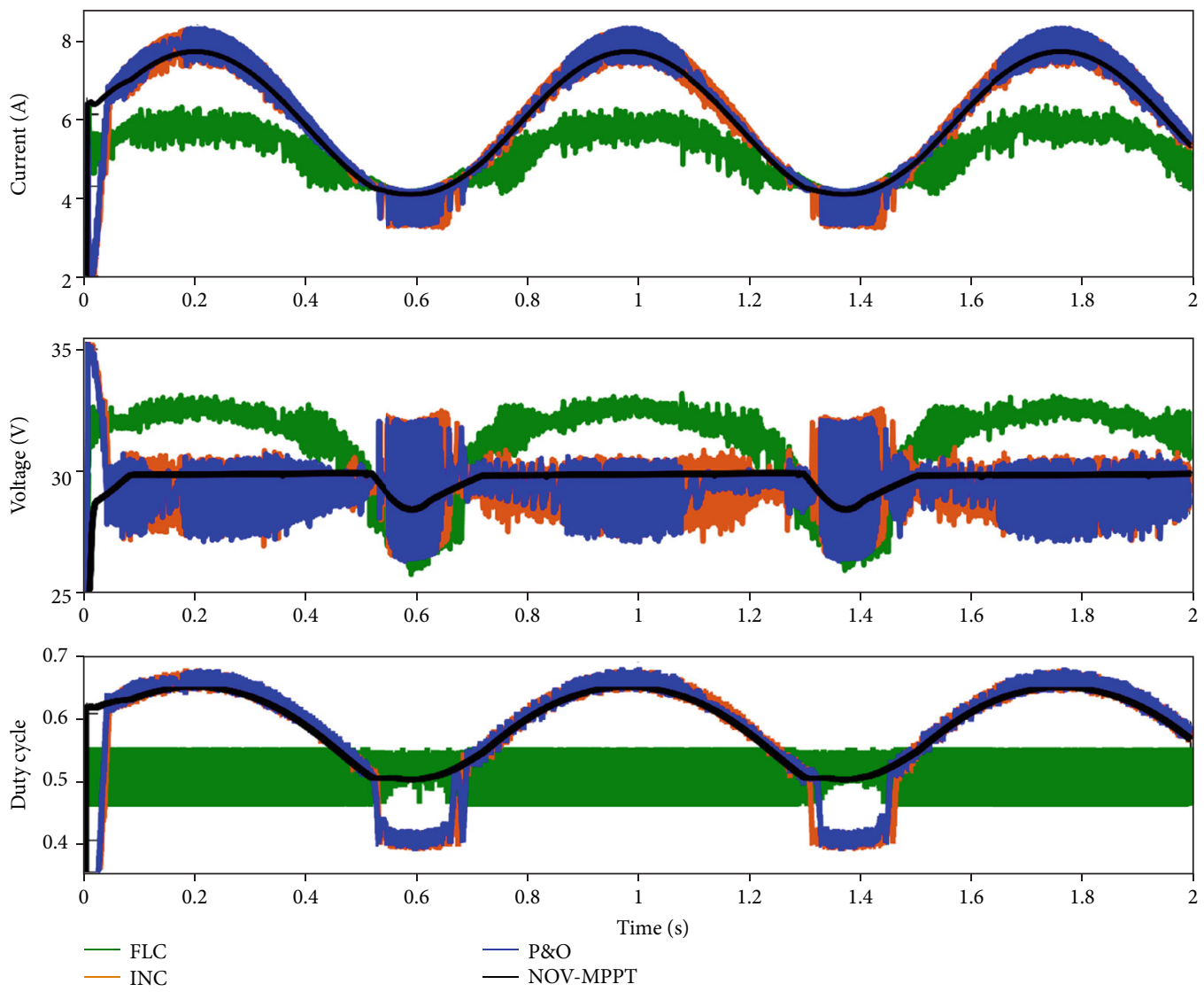

FIGURE 15: PV output current and voltage with duty cycle simulation result comparison of the proposed MPPT with the P\&O, INC, and FLC MPPT methods under the solar irradiation variation scenario III. 


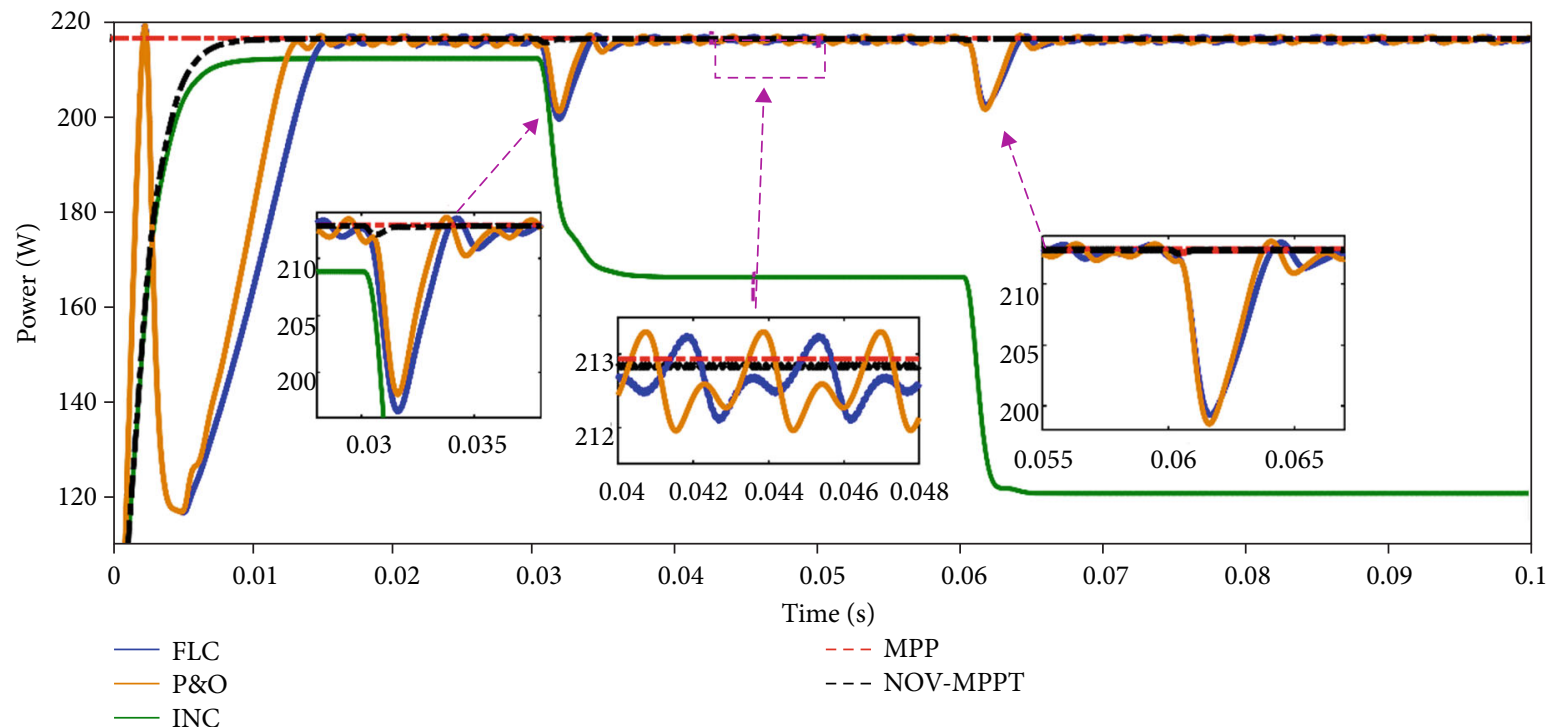

Figure 16: PV output power simulation comparison of the proposed MPPT with the P\&O, INC, and FLC MPPT algorithms under the load variation scenario.

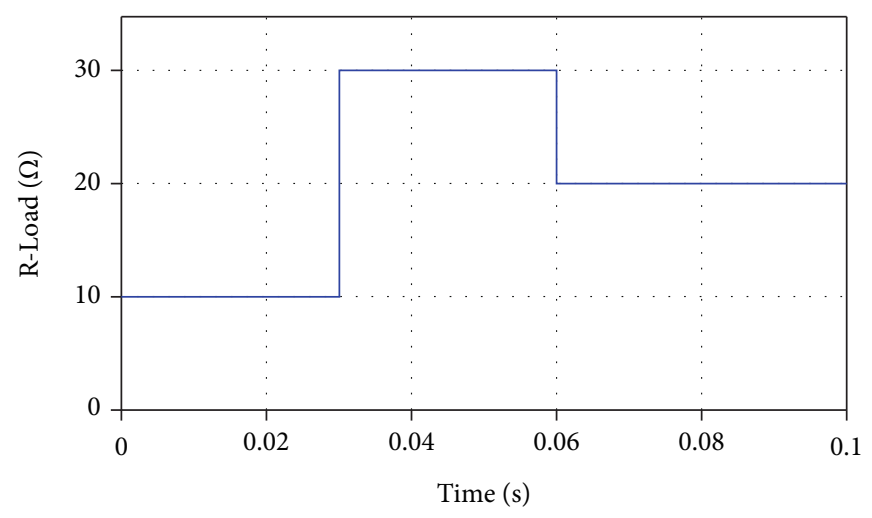

FIGURE 17: Load variation scenario profile.

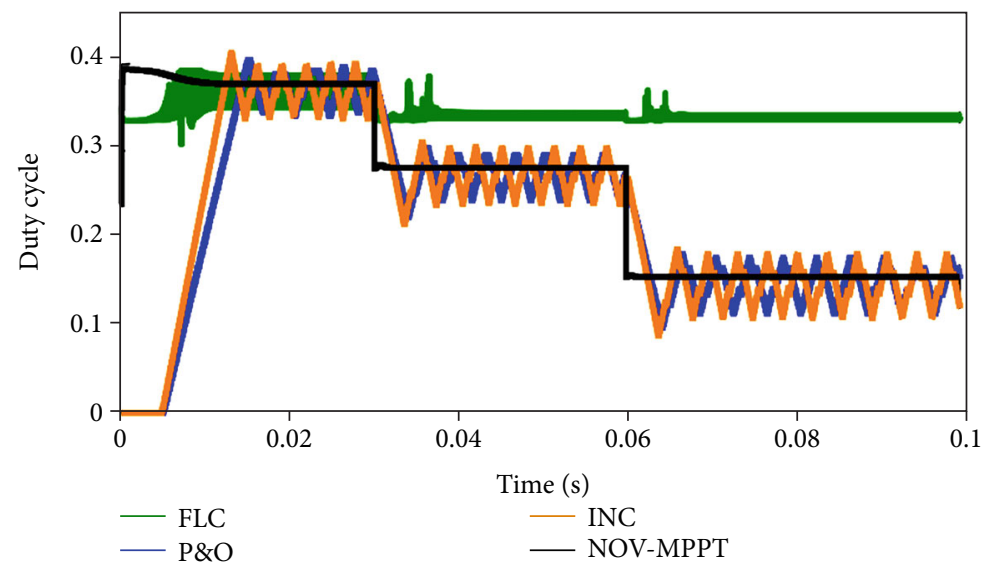

FIGURE 18: Output duty cycle simulation results under the load variation scenario. 
TABLE 2: Average efficiency comparison of MPPT methods under MATLAB/Simulink environment.

\begin{tabular}{lcccc}
\hline & \multicolumn{4}{c}{$\begin{array}{c}\text { Average efficiency (\%) } \\
\text { Solar irradiation variation }\end{array}$} \\
\hline MPPT methods & Scenario I & Scenario II & Scenario III & STC conditions \\
P\&O & 99.12 & 99.12 & 98.52 & 96.95 \\
INC & 99.11 & 99.13 & 98.32 & 97.03 \\
FLC & 80.98 & 76.8 & 88.68 & 77.14 \\
Proposed & 99.40 & 99.86 & 99.57 & 99.76 \\
\hline
\end{tabular}

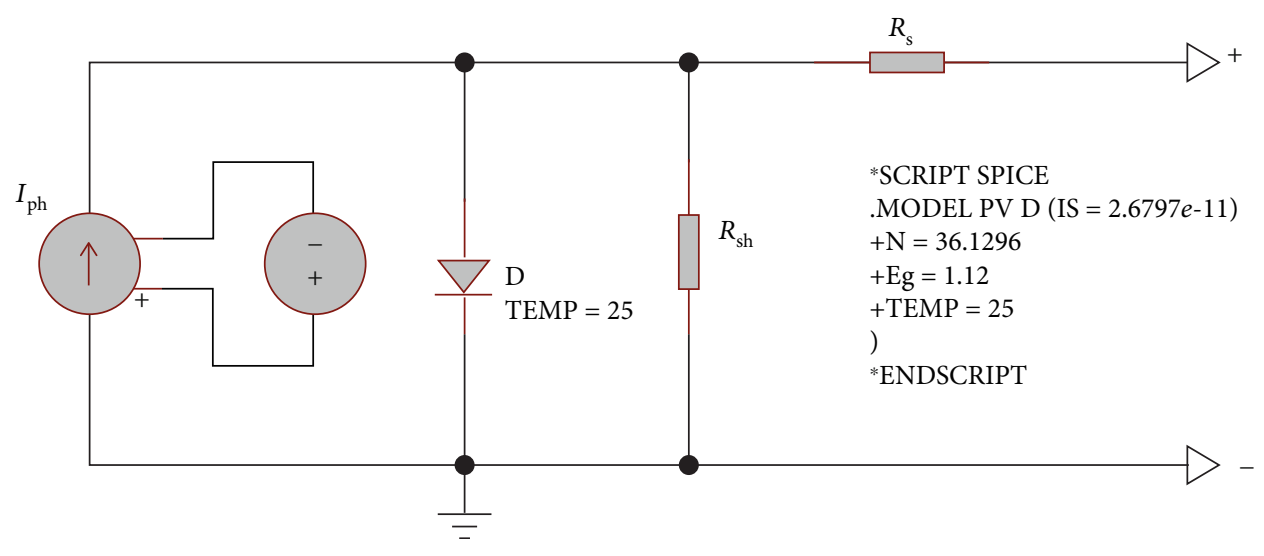

Figure 19: PV generator circuit on Proteus environment.

and also to examine its tracking performance and accuracy, where a sine form of insolation levels $\left(500 \mathrm{~W} / \mathrm{m}^{2}\right.$ $1100 \mathrm{~W} / \mathrm{m}^{2}$ ) is applied as shown in Figure 9.

The simulation results of the novel MPPT technique compared with the P\&O, INC, and FLC MPPT algorithms under scenario III are reported in Figures 14 and 15. By comparing these simulation results, especially, the PV output power curves, it can be noticeable the highest performance tracking of the proposed MPPT technique of the real MPP during the whole scenario III time. Firstly, the proposed MPPT technique is able to reach the MPP exactly and with less convergence time ( 9.5 milliseconds) as observed in the left below zoomed portion. In addition, it presents a high accuracy to follow and track the available MPP with zero oscillation in the entire simulation time as shown in the zoomed portions of Figure 14. Thus, the power losses are neglected. In the contrast, the P\&O and INC MPPT methods can be able to follow the MPP under the overall insolation scenario III, but they exhibit slow converging time (35 and 41 milliseconds, respectively) and large oscillations, especially, at low insolation level as shown in the zoomed views of Figure 14, whereas the FLC MPPT method has a bad tracking performance among all MPPT methods.

Furthermore, Figure 15 presents the PV output current and voltage and the duty cycle of the boost converter of the novel MPPT controller compared with the P\&O, INC, and FLC MPPT algorithms. The comparison reveals that the novel MPPT controller performs better in the case of the PV current and voltage stability, which is a result of the accurate duty cycle generated.
TABLE 3: PV generator characteristics at STC.

\begin{tabular}{lc}
\hline Characteristics & Value \\
\hline MPP maximum power $\left(P_{\mathrm{mpp}}\right)$ & $17 \mathrm{~W}$ \\
Voltage at $\operatorname{MPP}\left(V_{\mathrm{mpp}}\right)$ & $18.8 \mathrm{~V}$ \\
Current at $\operatorname{MPP}\left(I_{\mathrm{mpp}}\right)$ & $0.9 \mathrm{~A}$ \\
Short circuit current $\left(I_{\mathrm{sc}}\right)$ & $1.01 \mathrm{~A}$ \\
Open circuit voltage $\left(V_{\mathrm{oc}}\right)$ & 22.5 \\
Temperature coefficient of $V_{\mathrm{oc}}$ & $-0.35 \%{ }^{\circ} \mathrm{C}$ \\
Temperature coefficient of $I_{\mathrm{sc}}$ & $0.043 \%{ }^{\circ} \mathrm{C}$ \\
Photo current $\left(I_{\mathrm{ph}}\right)$ & $1.173 \mathrm{~A}$ \\
Saturation current $\left(I_{s}\right)$ & $2.6797 e-11 \mathrm{~A}$ \\
Ideality factor & 1.0036 \\
Shunt resistor $\left(R_{\mathrm{sh}}\right)$ & $405.96 \Omega$ \\
\hline
\end{tabular}

4.4. Load Variation. Figure 16 shows the output simulation results of the proposed MPPT tactic compared to the $\mathrm{P} \& \mathrm{O}$, INC, and FLC MPPT algorithms under the load scenario variation shown in Figure 17. The solar irradiation and temperature conditions are at STC conditions $\left(1000 \mathrm{~W} / \mathrm{m}^{2}\right.$ and $25^{\circ} \mathrm{C}$ ) during the whole test period.

From the output simulation results of the load variation scenario, the fast location of the MPP is done using the novel MPPT method, with neglected oscillations, while INC and P\&O MPPT methods present high oscillations around the MPP, and the P\&O method is the slowest one to locate the 


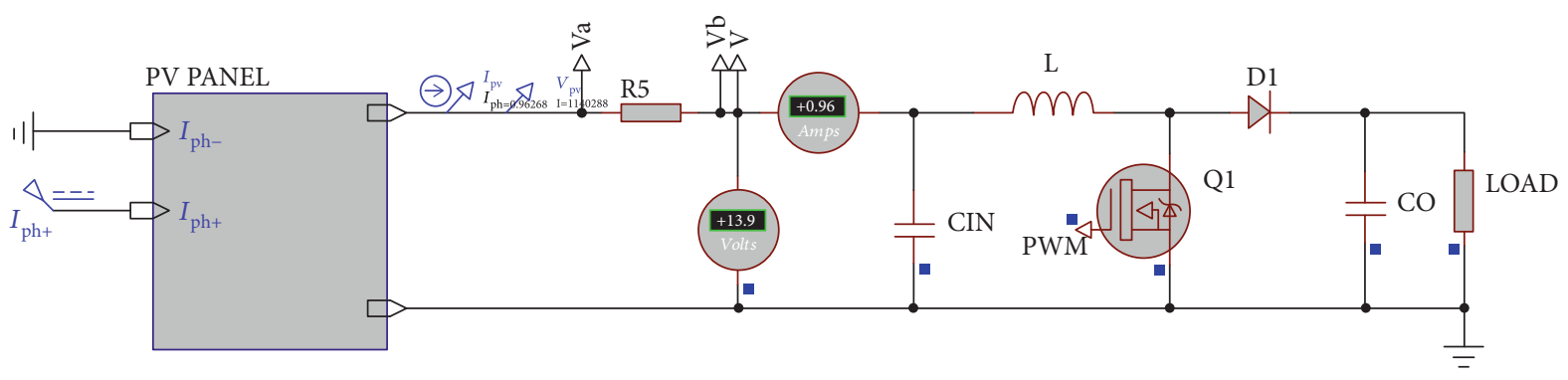

Figure 20: PV panel and DC-DC boost converter with a resistive load on Proteus environment.

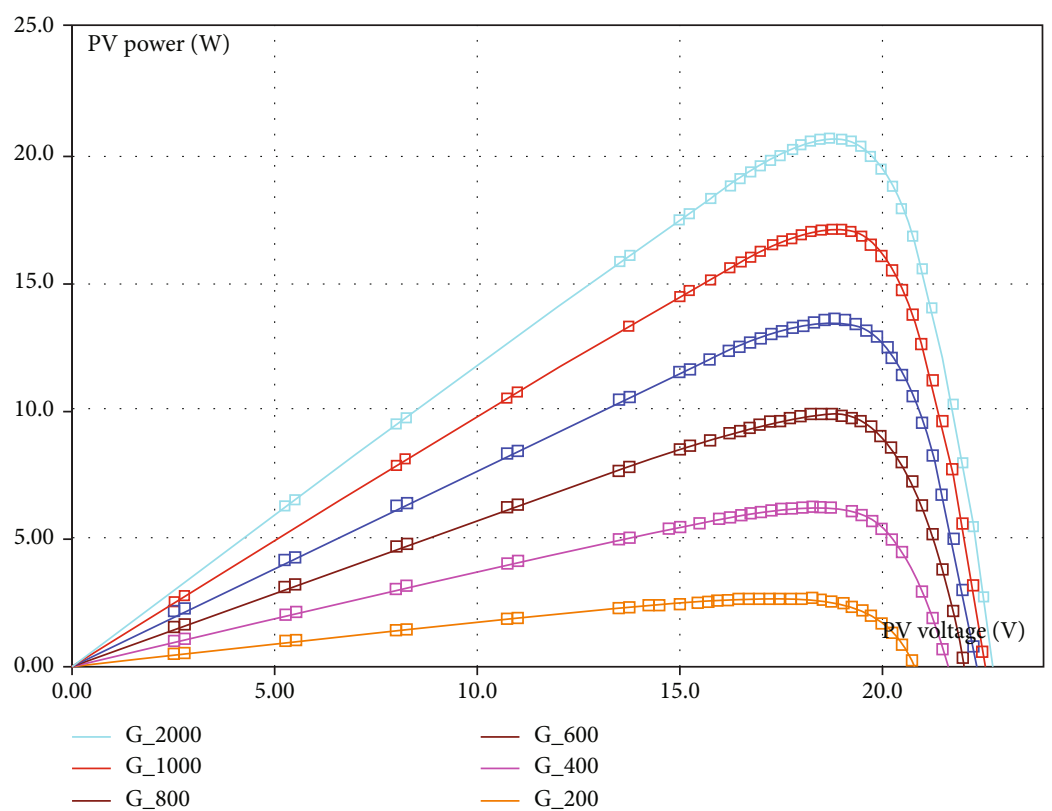

Figure 21: P-V curve of the PV panel under STC condition.

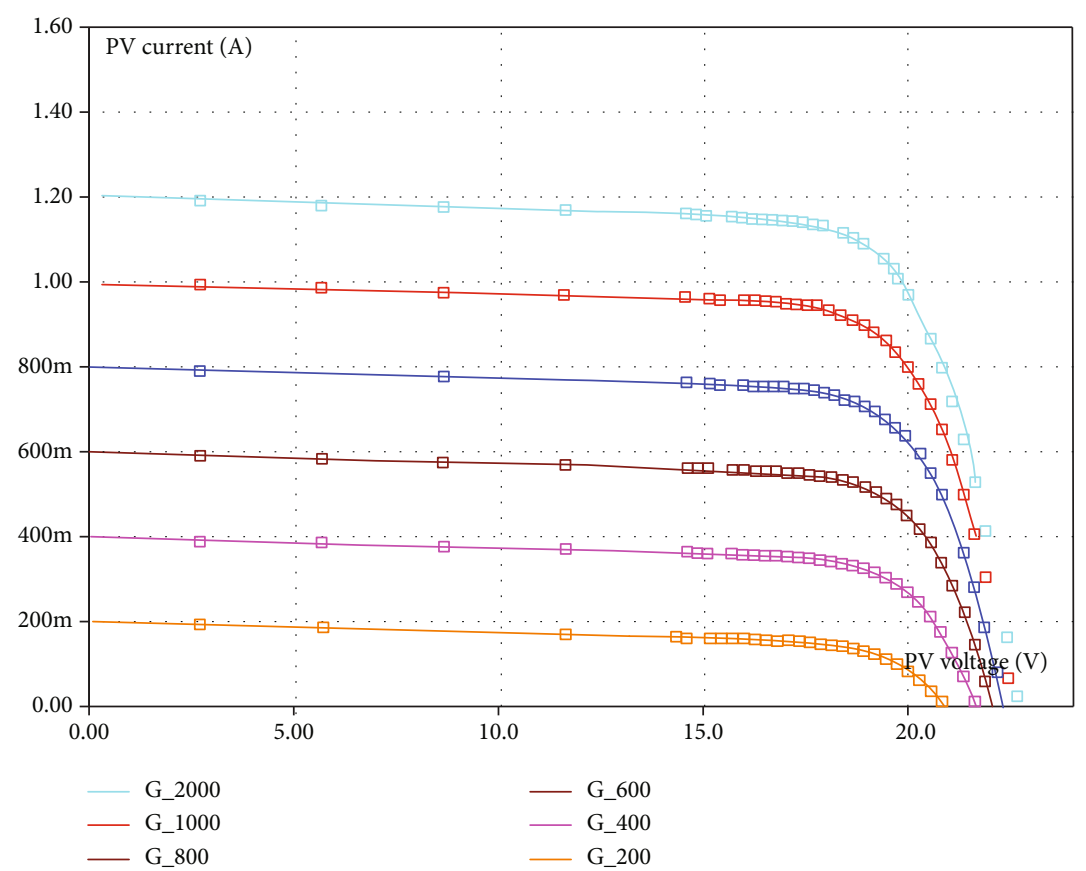

FIgURe 22: I-V curve of the PV panel under STC condition. 


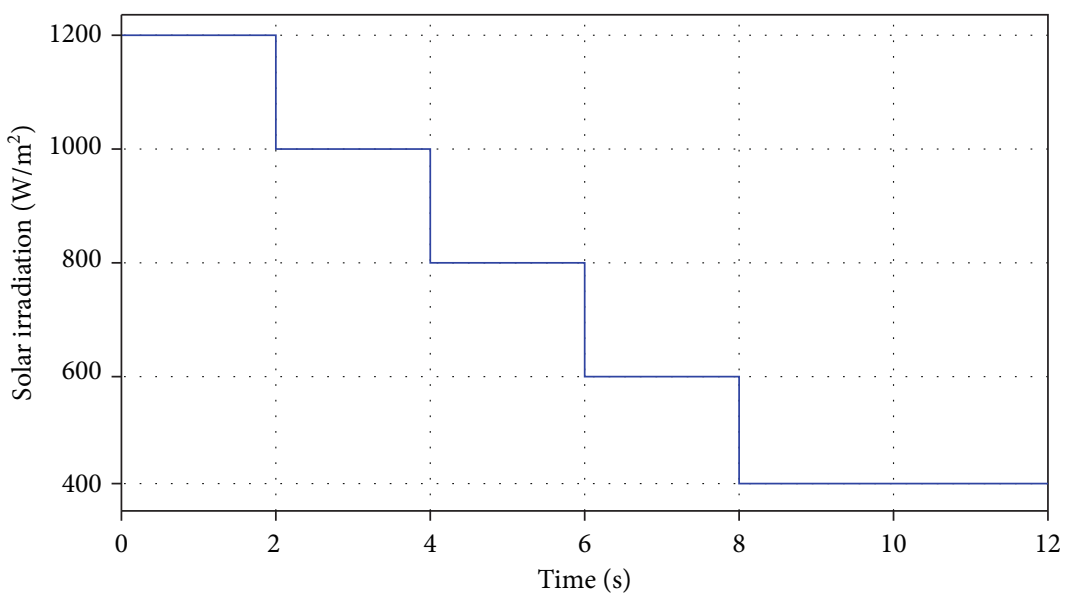

FiguRE 23: Sudden solar irradiation variation curve.

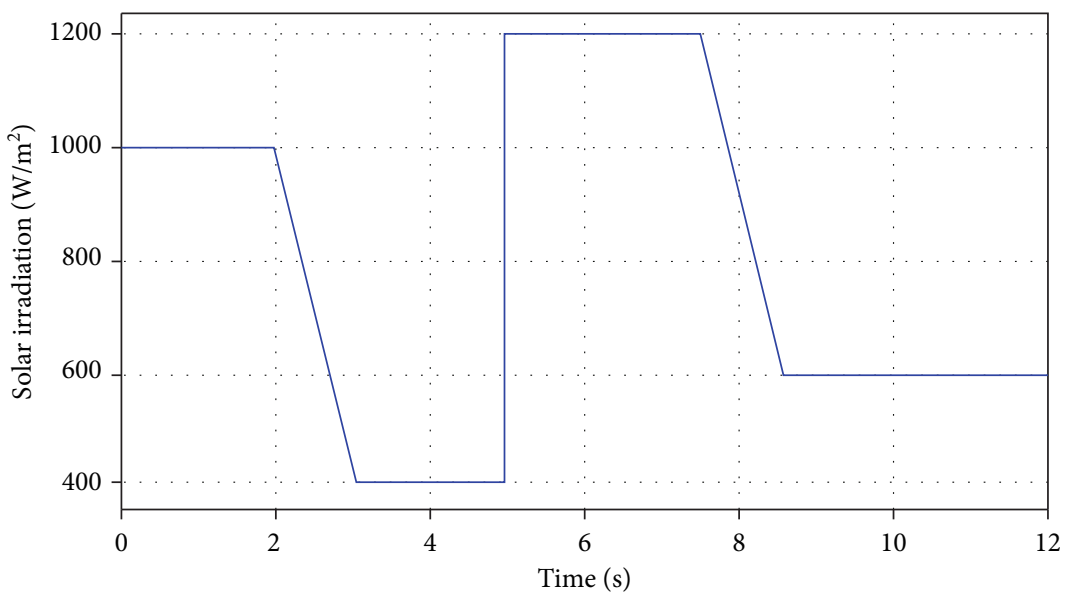

FIgURE 24: Test III curve of solar irradiation variation.

MPP. As shown in the power waveforms of load variation in Figure 16, the proposed MPPT algorithm has a high tracking speed, where it can track the MPP at a time of 0.007 seconds. In contrast, the MPP is reached in a time of 0.013 and 0.015 seconds in case of using the INC and P\&O MPPT methods, respectively.

In the case of the FLC MPPT controller, it is noticeable that it loses its tracking direction as soon as the variation of the load is detected. Thus, the boost converter's duty ratio has remained unchanged as can be seen from Figure 18. However, as observed in the zoomed portions of Figure 18, there are large overshoots of the PV power at the load variation and huge ripples around the MPP at steady-state operation when using the P\&O and INC MPPT methods. On the other hand, the novel MPPT tactic tracks the available maximum power almost perfectly with zero steady-state error, specifically when the load variation is detected.

Table 2 presents the comparison results of MPPT methods in terms of average efficiency during the overall simulation scenario period, where the average efficiency of the proposed MPPT technique is the best one among all
MPPT algorithms, and it is between $99.40 \%$ and $99.86 \%$ under all scenario situations.

4.5. Proteus Environment Implementation. Proteus platform is one of the best and simple environments implementation addressed to the PV systems. Furthermore, thanks to its simplicity of work and the large libraries of various electronic components that provide, Proteus software is one of the most frequently used simulation software. The Arduino UNO board with the microcontroller AT Mega328 is one of among components that can be used flexibly in the Proteus environment [17].

4.6. Implementation of a PV Generator on Proteus Environment. The PV generator circuit used in this simulation on the Proteus environment is shown in Figure 19, where its characteristics are given in Table 3 and the block $\mathrm{PV}$ generator and the DC-DC boost converter with resistive load are shown in Figure 20.

The power and current curves according to the voltage under different irradiation levels with a constant temperature of $25^{\circ} \mathrm{C}$ are shown in Figures 21 and 22, respectively. 


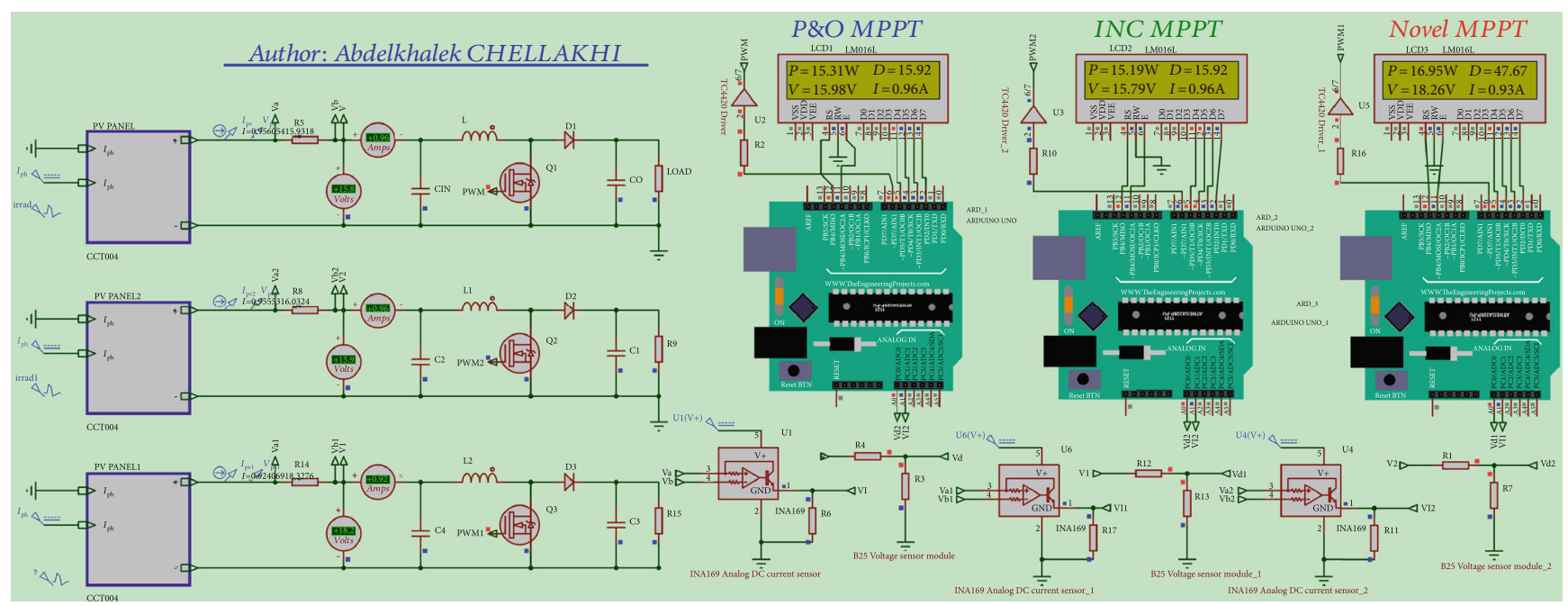

(a)

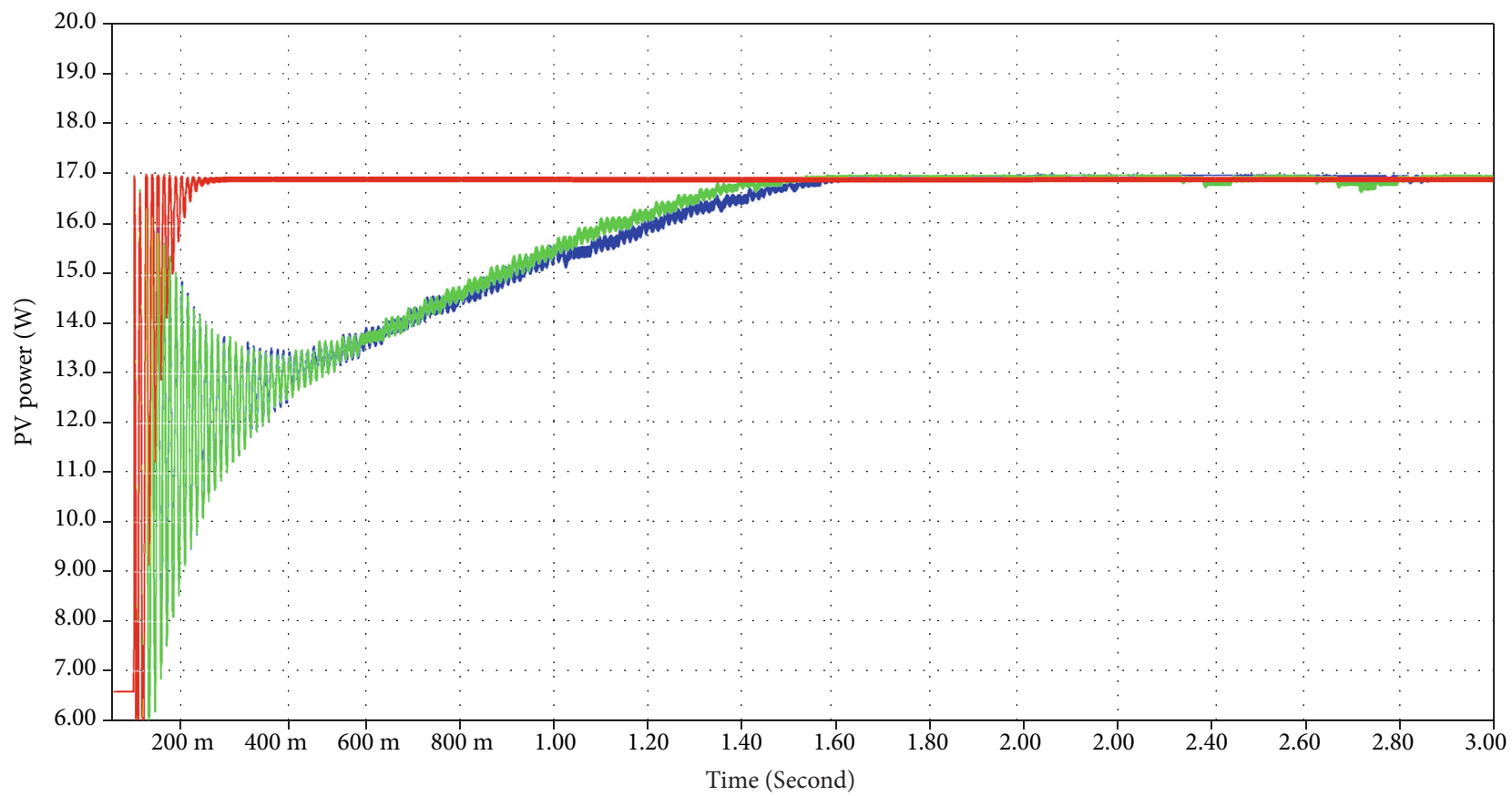

$\begin{array}{ll}- & P_{\mathrm{pv} \_} \text {P\&O MPPT } \\ - & P_{\mathrm{pv}-\mathrm{INC} \text { MPPT }} \\ - & P_{\mathrm{pv} \_} \text {Novel MPPT }\end{array}$

(b)

FIGURE 25: Simulation result comparison of the novel MPPT control with the P\&O and INC MPPT methods under the test I (STC). (a) Proteus environment implementation with Arduino boards and LCDs and (b) PV generator output power.

4.7. Implementation of the New MPPT Controller under Proteus-Based Arduino UNO (ATMega328) and 16-Bit LCD Display. The novel MPPT controller is implemented on the Arduino UNO board with ATMega328 controller, and to better observe the PV generator power, current, and voltage with the duty cycle of the boost converter measurements, a 16-bit LCD is added.

To show the robustness of the novel MPPT controller, it is compared with the $\mathrm{P} \& \mathrm{O}$ and INC MPPT algorithms, under three tests of solar irradiation conditions, where the temper- ature was kept constant at $25^{\circ} \mathrm{C}$. The insolation level was $1000 \mathrm{~W} / \mathrm{m}^{2}$ under test I, while it fast continually decreased under test II from $1200 \mathrm{~W} / \mathrm{m}^{2}$ to $400 \mathrm{~W} / \mathrm{m}^{2}$ as shown in Figure 23. In addition, Figure 24 presents test III, where the solar irradiation varies with slow and sudden transition procedure between four levels $1200 \mathrm{~W} / \mathrm{m}^{2}, 1000 \mathrm{~W} / \mathrm{m}^{2}$, $600 \mathrm{~W} / \mathrm{m}^{2}$, and $400 \mathrm{~W} / \mathrm{m}^{2}$.

In this simulation, three PV generators and three boost converters are implemented, where the three MPPT controllers are employed on Arduino boards, and to measure the PV 


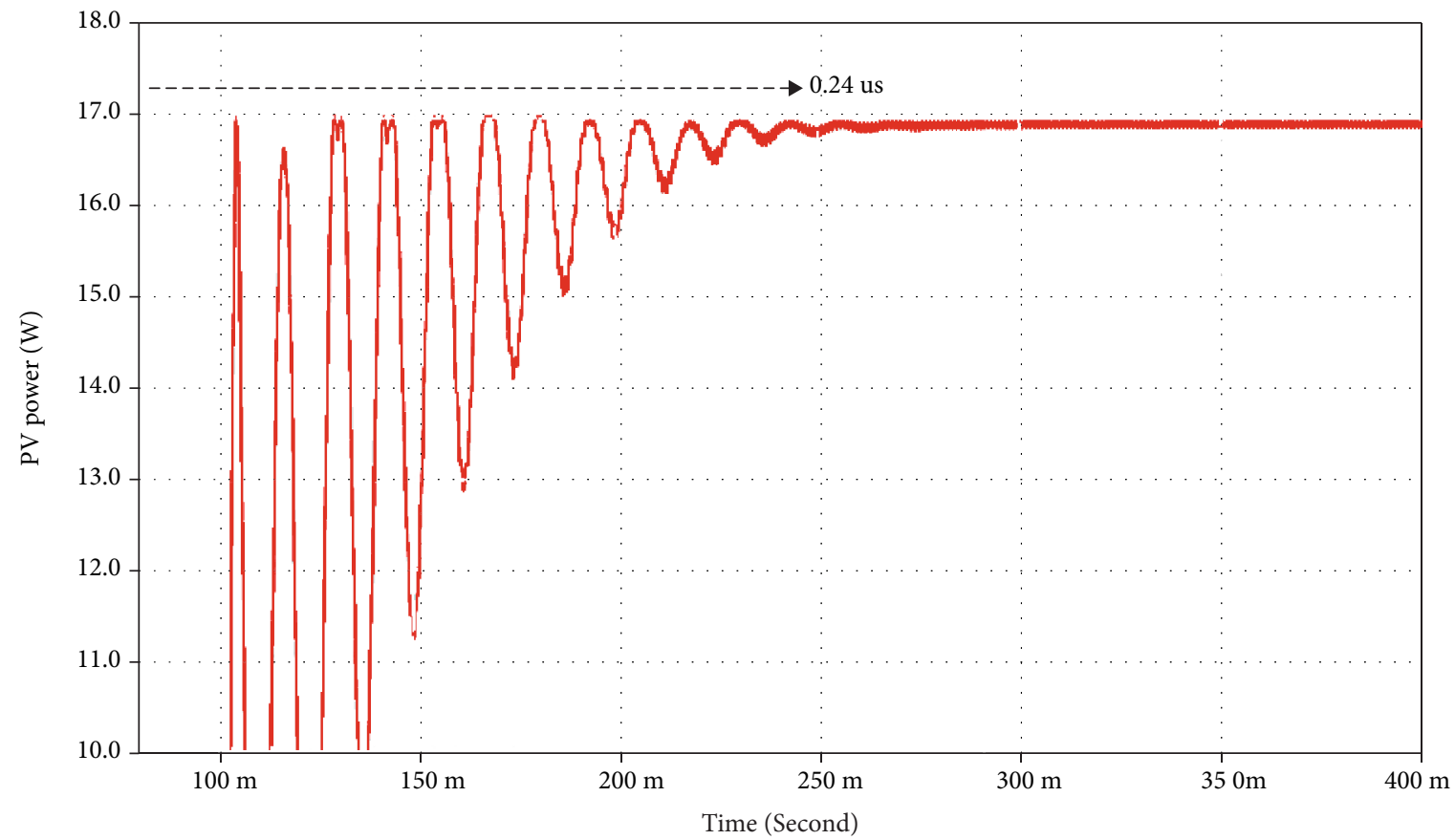

(a)

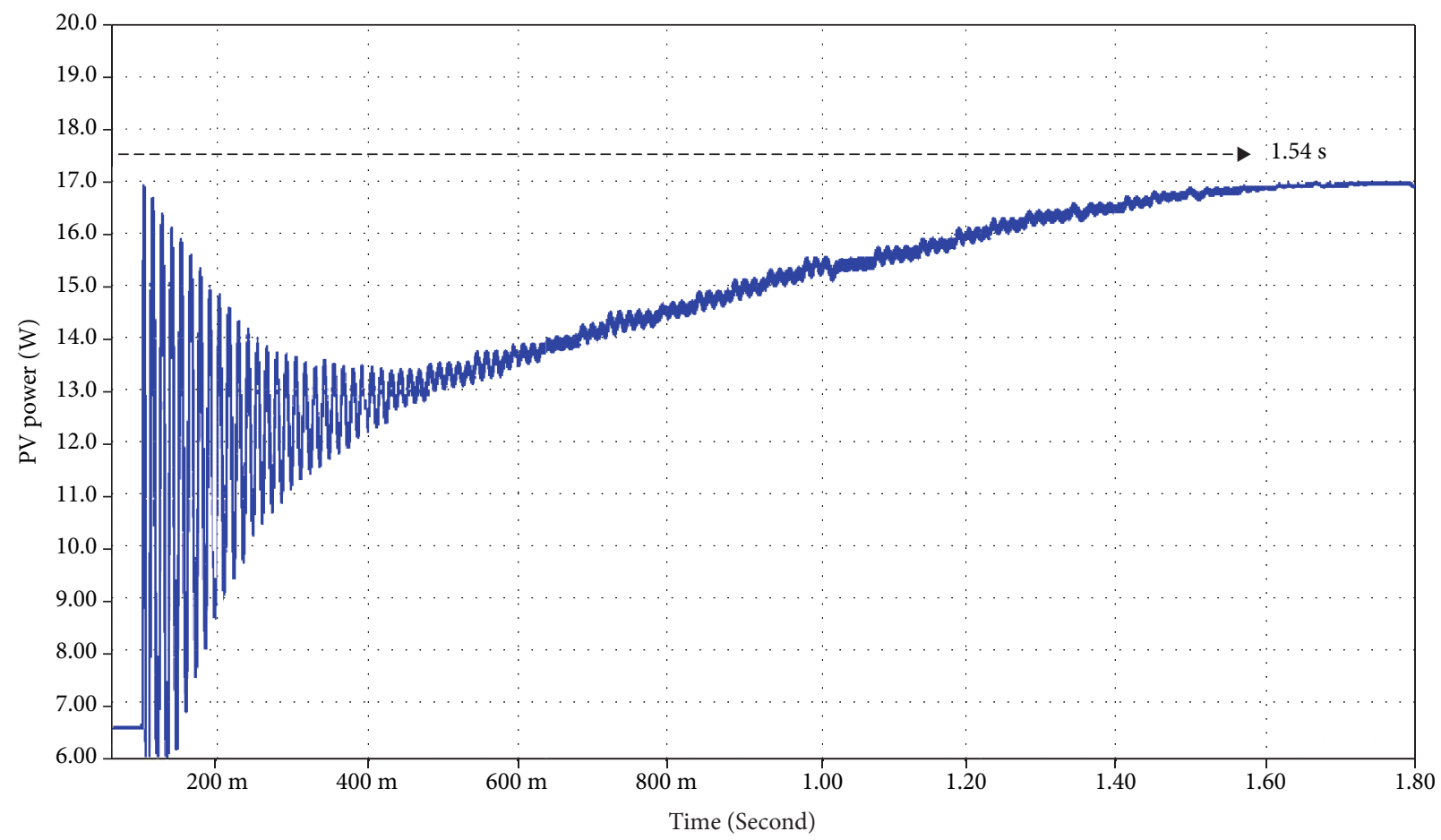

$-P_{\mathrm{pv} \_} \mathrm{P} \& \mathrm{O}$ MPPT

(b)

Figure 26: Continued. 


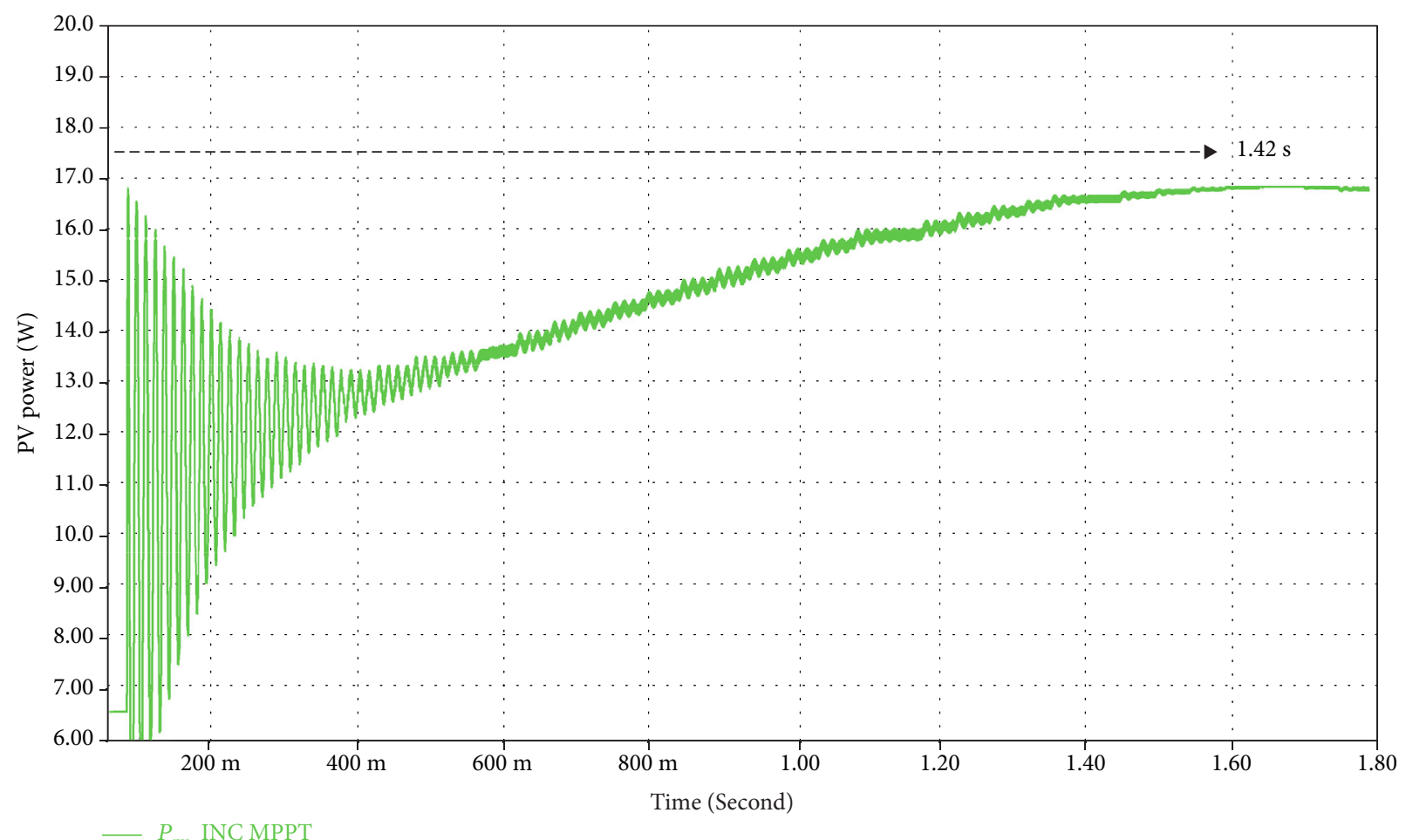

(c)

Figure 26: Time convergence of the three MPPT controllers under test I: (a) novel MPPT, (b) P\&O MPPT, and (c) INC MPPT.

current and voltage, an INA169 current sensor and a B25 voltage sensor are used.

4.8. Simulation Results under the Test I Insolation Condition. Figure 25 shows the simulation result comparison of the three MPPT controllers under standard test conditions (STC) $\left(1000 \mathrm{~W} / \mathrm{m}^{2}, 25^{\circ} \mathrm{C}\right)$ on the Proteus environment with Arduino boards and LCDs.

The performance of the new MPPT controller is observed according to Figures 25 and 26, where it is obvious that our MPPT approach tracks the maximum power point (MPP) in a time that does not even exceed 0.24 microseconds $(\mu \mathrm{s})$ and with zero oscillation. On the contrary, the other MPPT algorithms, P\&O and INC, cannot reach the MPP except in a time exceeding 1.54 and 1.42 seconds (s), respectively, with observable oscillations around the MPP.

Besides, the new MPPT approach can achieve an efficiency of $99.41 \%$ or instead of an efficiency of $98.82 \%$ and 98.23\% for the P\&O and INC algorithms, respectively.

4.9. Simulation Results under the Test II Insolation Conditions. Figure 27 shows the simulation results of the output powers of the PV generators tracked by the three MPPT controllers under the test II, which presents sudden decrease of solar irradiation variation from $1200 \mathrm{~W} / \mathrm{m}^{2}$ to $400 \mathrm{~W} / \mathrm{m}^{2}$ with a constant temperature of $25^{\circ} \mathrm{C}$ as reported in Figure 23. It is noticeable from Figure 27 that the novel MPPT tactic follows exactly the real output PV power according to the solar irradiation variation curve. Also, it provides a better performance and high speed of convergence towards the MPP under the fast change of the solar irradiation. On the other hand, the P\&O and INC MPPT algorithms are very clearly influenced by the sudden change of the solar irradiation and provide nonstability around the MPP with slow-speed convergence.

4.10. Simulation Results under the Test III Insolation Conditions. The test III shown in Figure 24 presents a combination of difficult insolation transitions and different insolation levels, in order to examine the performance tracking and accuracy of the novel MPPT controller.

The simulation result comparison reported in Figure 28 reveals that the novel MPPT controller performs better, by eliminating the steady-state error and by responding faster and accurate to the variation in insolation level and transition condition. On the other hand, the P\&O and INC MPPT algorithms clearly loss their tracking and cannot track the real MPP when the solar irradiation changed. Thus, high power losses are mitigated in case of using the proposed MPPT technique.

4.11. Evaluation. Table 4 shows the comparison between the proposed MPPT technique and other MPPT algorithms published in scientific literature. This comparison is based on simulation results carried out under MATLAB/Simulink environment. By comparing these results, it can be seen that the proposed MPPT method has the highest efficiency and speed of tracking with the lowest time converging. In addition, the proposed MPPT method is obviously reducing the 


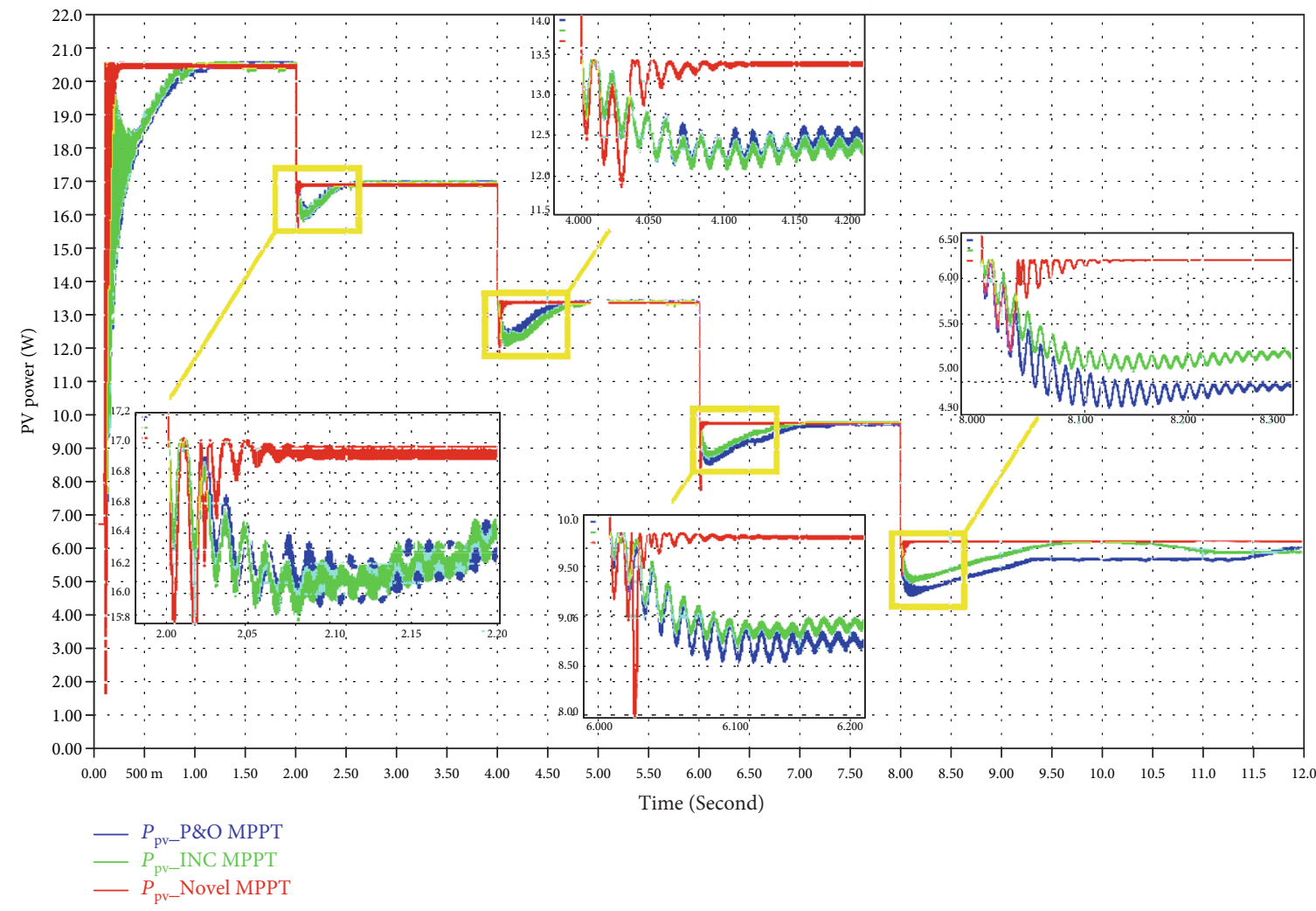

FIGURE 27: Simulation result comparison of the three MPPT controllers under sudden variation of the solar irradiation conditions.

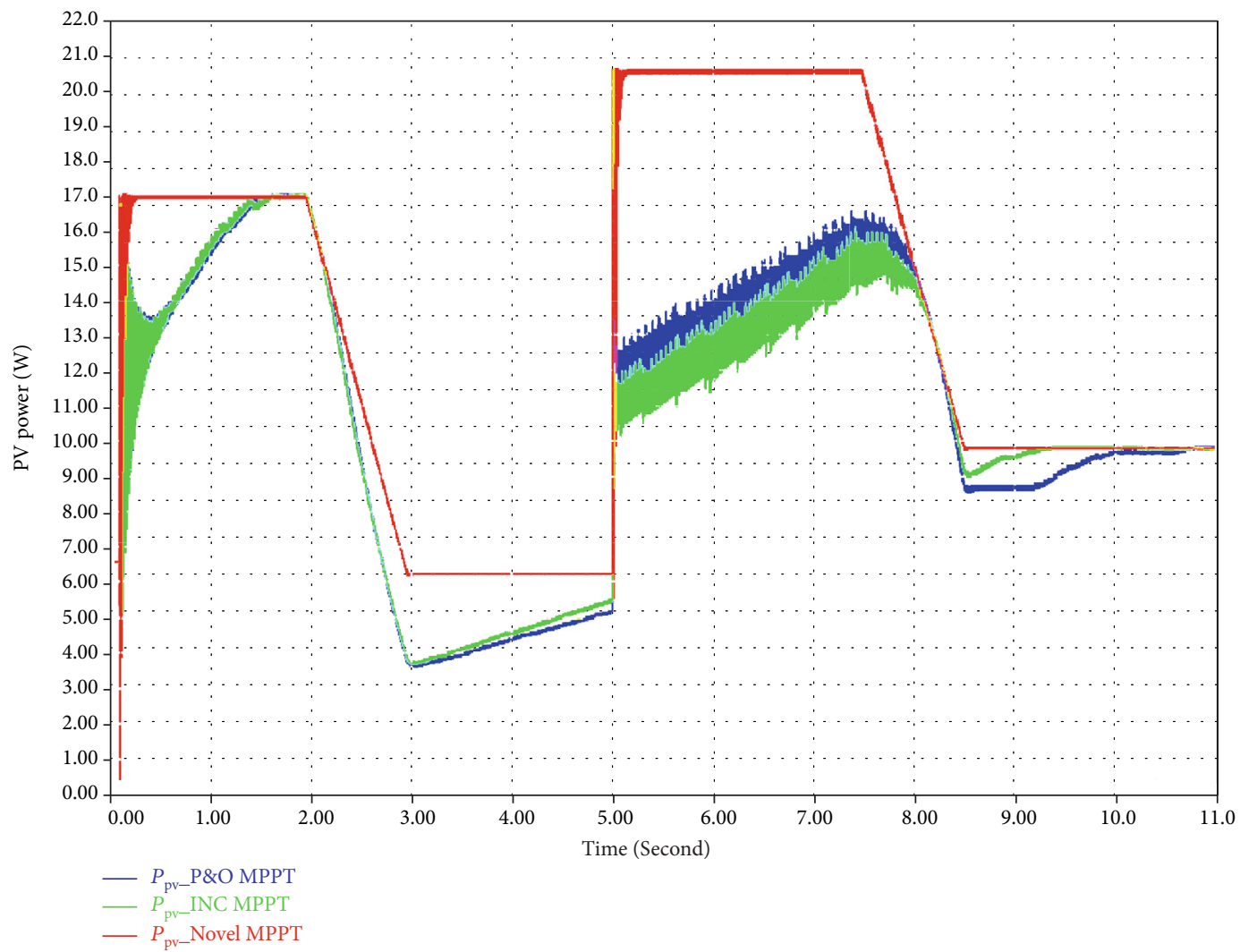

FIGURE 28: Simulation result comparison of the three MPPT controllers under the test III of the solar irradiation conditions. 
TABLE 4: Comparison of the proposed MPPT technique with other MPPT techniques proposed in the scientific literature.

\begin{tabular}{|c|c|c|c|c|}
\hline Scenario & {$[18]$} & [5] & {$[4]$} & Proposed \\
\hline Steady-state oscillation & Neglected & Neglected & Small & Neglected \\
\hline Efficiency (\%) under STC & 99.27 & 97.67 & 99.5 & 99.76 \\
\hline Tracking steps during increase in solar irradiation level & 4 steps & 3 steps & - & 1 step \\
\hline Convergence time $(\mathrm{s})$ & 0.2 & 0.33 & 0.021 & 0.007 \\
\hline Tracking speed under sudden variation of insolation & Medium & Fast & Fast & Very fast \\
\hline
\end{tabular}

steps of tracking during the sudden variation of solar irradiation compared with the other MPPT algorithms.

\section{Conclusion}

In this paper, a novel MPPT tactic has been implemented and analyzed in order to harvest the power generation from photovoltaic systems. Different scenarios of sudden solar irradiation and load variation levels are adopted in order to examine the efficiency and performance of the novel MPPT technique using MATLAB/Simulink and Proteus simulation environments. The tracking accuracy is improved, and the steadystate ripple is eliminated using the novel algorithm. Furthermore, the novel MPPT tactic can track MPP faster compared to other conventional MPPT algorithms P\&O, INC, and FLC under sudden solar irradiation and load variation, which can improve the reduction of the power losses. The simulation results demonstrate the superior performance and efficiency, which can be reached using the proposed MPPT tactic over traditional MPPT methods such as P\&O, INC, and FLC. Furthermore, a low-cost system component is required (Arduino UNO board) to implement the novel MPPT controller without extra control mechanisms, which is simpler than other MPPT algorithms.

\section{Data Availability}

The data used to support the findings of this study are available from the corresponding author upon request.

\section{Conflicts of Interest}

The authors declare that there is no conflict of interest regarding the publication of this paper.

\section{References}

[1] C. Abdelkhalek, E. B. Said, and A. Younes, "A novel MPPT tactic for PV systems with fast-converging speed and zero oscillation," in 2020 5th International Conference on Renewable Energies for Developing Countries (REDEC), Marrakech, Morocco, Morocco, 2020.

[2] M. A. Elgendy, B. Zahawi, and D. J. Atkinson, "Operating characteristics of the $\mathrm{P} \& \mathrm{O}$ algorithm at high perturbation frequencies for standalone PV systems," IEEE Transactions on Energy Conversion, vol. 30, no. 1, pp. 189-198, 2015.

[3] C. Abdelkhalek, E. L. B. Said, and A. Younes, "An improved MPPT tactic for PV system under temperature variation," in 2019 8th International Conference on Systems and Control (ICSC), Marrakech, Morocco, Morocco, 2019.
[4] U. Yilmaz, O. Turksoy, and A. Teke, "Improved MPPT method to increase accuracy and speed in photovoltaic systems under variable atmospheric conditions," International Journal of Electrical Power \& Energy Systems, vol. 113, pp. 634-651, 2019.

[5] L. Xu, R. Cheng, and J. Yang, "A new MPPT technique for fast and efficient tracking under fast varying solar irradiation and load resistance," International Journal of Photoenergy, vol. 2020, 18 pages, 2020.

[6] N. Femia, G. Petrone, G. Spagnuolo, and M. Vitelli, "Optimization of perturb and observe maximum power point tracking method," IEEE Transactions on Power Electronics, vol. 20, no. 4, pp. 963-973, 2005.

[7] M. A. Elgendy, B. Zahawi, and D. J. Atkinson, "Assessment of the incremental conductance maximum power point tracking algorithm," IEEE Transactions on sustainable energy, vol. 4, no. 1, pp. 108-117, 2013.

[8] A. Safari and S. Mekhilef, "Simulation and hardware implementation of incremental conductance MPPT with direct control method using cuk converter," IEEE Transactions on Industrial Electronics, vol. 58, no. 4, pp. 1154-1161, 2011.

[9] M. Lasheen and M. Abdel-Salam, "Maximum power point tracking using Hill Climbing and ANFI techniques for PV applications: a review and a novel hybrid approach," Energy Conversion and Management, vol. 171, pp. 1002-1019, 2018.

[10] H. D. Liu, C. H. Lin, K. J. Pai, and Y. L. Lin, "A novel photovoltaic system control strategies for improving hill climbing algorithm efficiencies in consideration of radian and load effect," Energy Conversion and Management, vol. 165, pp. 815-826, 2018.

[11] S. Ozdemir, N. Altin, and I. Sefa, "Fuzzy logic based MPPT controller for high conversion ratio quadratic boost converter," International Journal of Hydrogen Energy, vol. 42, no. 28, pp. 17748-17759, 2017.

[12] P. C. Cheng, B. R. Peng, Y. H. Liu, Y. S. Cheng, and J. W. Huang, "Optimization of a fuzzy-logic-control-based MPPT algorithm using the particle swarm optimization technique," Energies, vol. 8, no. 6, pp. 5338-5360, 2015.

[13] M. Vardia, N. Priyadarshi, I. Ali, F. Azam, and A. K. Bhoi, "Design of Wind Energy Conversion System under Different Fault Conditions," in Advances in Greener Energy Technologies, Springer, Singapore, 2020.

[14] U. Yilmaz, A. Kircay, and S. Borekci, "PV system fuzzy logic MPPT method and PI control as a charge controller," Renewable and Sustainable Energy Reviews, vol. 81, pp. 994-1001, 2018.

[15] A. M. Noman, K. E. Addoweesh, and H. M. Mashaly, "A fuzzy logic control method for MPPT of PV systems," in IECON 2012-38th Annual Conference on IEEE Industrial Electronics Society, Montreal, QC, Canada, Canada, 2012. 
[16] S. Necaibia, M. S. Kelaiaia, H. Labar, A. Necaibia, and P. O. Logerais, "Boost Chopper implementation based on variable MPPT duty cycle control applied to photovoltaic systems," in 2017 International Renewable and Sustainable Energy Conference (IRSEC), Tangier, Morocco, 2018.

[17] S. Motahhir, A. Chalh, A. El Ghzizal, and A. Derouich, "Development of a low-cost PV system using an improved INC algorithm and a PV panel Proteus model," Journal of Cleaner Production, vol. 204, pp. 355-365, 2018.

[18] K. S. Tey and S. Mekhilef, "Modified incremental conductance MPPT algorithm to mitigate inaccurate responses under fastchanging solar irradiation level," Solar Energy, vol. 101, pp. 333-342, 2014. 